NASA

Reference Publication 1322

November 1993

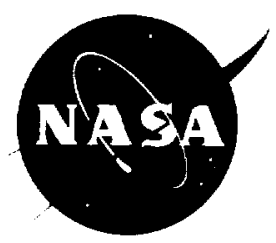

National Aeronautics and Space Administration

Scientific and Technical Information Branch

\section{Presenting the \\ Rain-Sea Interaction Facility}

Larry F. Bliven

NASA Goddard Space Flight Center

Wallops Flight Facility

Wallops Island, Virginia

Tonas M. Elfouhaily

L'Universite de Paris VII and XIII

Paris, France

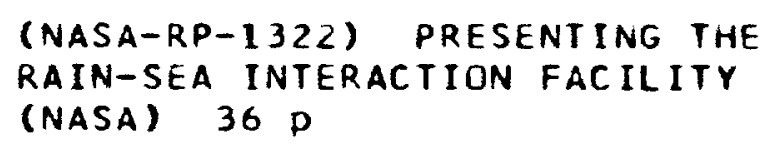

N94-21628

Unclas

$H 1 / 48 \quad 0198100$ 


\section{NASA \\ Reference \\ Publication}

1322

October 1993

\section{Presenting the \\ Rain-Sea Interaction \\ Facility}

Larry F. Bliven and Tonas M. Elfouhaily

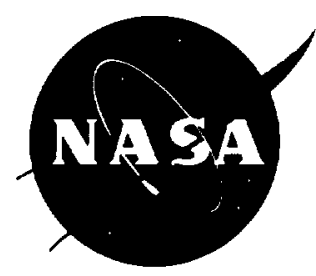




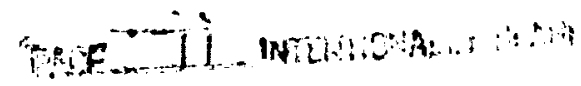




\section{Presenting The}

\section{Reuidn=Seal Interaction Facility}

Invitation: Everyone who wishes to participate in cooperative research and/or who wants to receive the facility's research publications as they periodically appear is invited to contact us at the address below:

Larry F. Bliven

Laboratory for Hydrospheric Processes

NASA GSFC

Wallops Flight Facility

Wallops Island, VA 23337 USA
804-824-2578 RSIF

804-824-1057 Office

804-824-1036 FAX

804-824-2526 Secretary

fbliven@gsfemail.nasa.gov

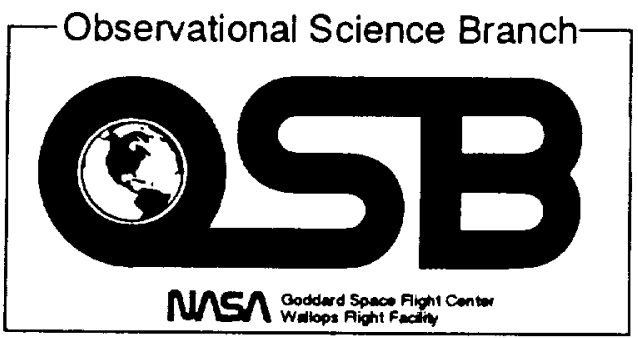

iii 
Abstract: The new Rain-Sea Interaction Facility (RSIF) has been established at GSFC/WFF and the first findings are presented in this report. The unique feature of this laboratory is the ability to systematically study microwave scattering from a water surface roughened by artificial rain, for which the droplets are at terminal velocity. The fundamental instruments and systems (e.g. the rain simulator, scatterometers and surface elevation probes) were installed and evaluated during these first experiments - so the majority of the data were obtained with the rain simulator at $1 \mathrm{~m}$ above the water tank. From these initial experiments, three new models have been proposed: the square-root function for NCS vs R, the loggaussian model for ring-wave elevation frequency spectrum, and the Erlang probability density distribution for backscattered power. Rain rate is the main input for these models, although the coefficients may be dependent upon other factors (drop-size distribution, fall velocity, radar configuration, etc.). The facility is functional and we foresee collaborative studies with investigators who are engaged in measuring and modeling rain-sea interaction processes.

Avant-propos: Une expérimentation de pluie simulée a été faite pour étendre à forts taux de pluie $\left(\mathrm{R} \mathrm{mm} \mathrm{hr}{ }^{-1}\right)$ le modèle à faibles taux proposé par Bliven pour la section radar efficace normalisée (NCS). La dépendance de la NCS est linéaire en fonction de faibles taux de pluie. Il a été démontre que pour ces conditions d'expérimentation la théorie de rétrodiffusion de Bragg pour les vagues annulaires est applicable. Ce papier rectifiera le domaine de validité du modèle linéaire et proposera un modèle plus général applicable aussi bien pour faible pluie que pour forte pluie.

En vue d'accomplir cette tâche, on proposera un modèle original pour la distribution de densité de probabilité des données radar. Egalement une étude de la topographie de surface est faite à l'aide d'une sonde d'élévation par capacitance, qui fournira les données nécessaires pour une intéressante modélisation de spectre d'élévation de surface en fréquence dans l'intervalle d'étude des vagues de type capillaire-gravités.

Le simulateur de pluie qui a servi à mener cette expérience sera décrit pour le lecteur dans le but de lui permettre de découvrir d'une part l'originalité de cette réalisation et d'autre part la capacité à simuler au mieux une précipitation naturelle. 


\section{TABLE OF CONTENTS}

$\begin{array}{ll}\text { 1. INTRODUCTION } & 1\end{array}$

2. BACKGROUND 2

3. RSIF DESCRIPTION AND EXPERIMENTAL CONDITIONS 3

4. NCS VERSUS R: SQUARE-ROOT MODEL 4

5. RING-WAVE SPECTRA: LOG-GAUSSIAN MODEL 5

6. RP PROBABILITY DENSITY DISTRIBUTIONS: ERLANG MODEL 9

$\begin{array}{ll}\text { 7. SUMMARY } & 10\end{array}$

$\begin{array}{lr}\text { 8. REFERENCES } & 11\end{array}$

$\begin{array}{ll}\text { 9. FIGURES } & 16\end{array}$ 



\section{Introduction}

Rain and wind measurements in oceanic regions will make significant contributions to weather monitoring and climate studies. Spaceborne instruments such as altimeters and scatterometers measure power levels of microwave echoes from the sea surface and since echo strength correlates with sea-surface roughness, particularly small-scale roughness, any processes that affect sea surface roughness can modify measurements. Nearly ubiquitous winds roughen the sea surface, so most data inversion algorithms deal with wind exclusively. Rain agitates the sea surface. Atmospheric attenuation and scattering by rain are included in two models that simulate satellite-based systems (at nadir by Meneghini and Atlas (1986) and at scatterometer angles by Sobieski et al. (1991)) - but the effects of rain on microwave scattering from the sea surface are yet to be included in space applications.

When a raindrop hits a water surface, it can generate a cavity with a crown, which collapses to form a vertical stalk of water, which subsides to spawn rings of gravity-capillary waves that propagate outward (Worthington (1882), Le Méhauté et al. (1987) and Le Méhauté (1988)). At grazing angles, Wetzel (1990) found from analysis of laboratory data that stalks are the dominant feature contributing to backscattered power. At incidence angles used from space, a dearth of data hampers validation of numerical models. Two recent studies by Bliven and Giovanangeli (1993) and Bliven et al. (1993) use $\mathrm{Ku}$ - and Ka-band scatterometers (30 degrees incidence angles and vertical polarization) to study scattering from a rain-roughened water surface for simulated light rains $\left(\mathrm{R}<30 \mathrm{~mm} \mathrm{hr}^{-1}\right)$ in a wind-wave tank. Those data show (a) that the dependence of Normalized Radar Cross-Section (NCS) on rainfall rate $R$ is well modeled by a linear function and that (b) there is evidence that the dominant scattering mechanism is Bragg scattering from ring-waves. Much more can be learned about microwave scattering from rain-roughened surfaces by conducting experiments that span a broader range of physical conditions. Higher rain rates obviously need to be studied and other rain-related topics include the effects of dropsize and fall velocity. On the other hand, microwave topics include scattering physics related to radar viewing angle, polarization, and microwave frequency.

A research facility was needed to allow these issues to be systematically investigated using both standard and specialized instrumentation in a setting that permits water drops to reach terminal velocity. Such a site was available at the Wallops Flight Facility and as part of this endeavor, the Rain-Sea Interaction Facility was established. Research being conducted at the RSIF is part of an ongoing international research program that includes numerical modeling of microwave scattering from the sea by scatterometers and altimeters (Sobieski $e t$ al. 1990) and simulations of scattering from rain- and wind-roughened seas in a laboratory wind-wave tank (Giovanangeli et al. 1991). The new RSIF is functional and open for cooperative investigations.

In this paper, we present a guide to papers pertaining to rain-sea interaction processes, a description of the new Rain-Sea Interaction Facility, and the first data sets from the RSIF are examined. The main objective was to obtain data over an extended range of rainfall rates to see if the linear relationship between NCS and R is robust. Two additional topics are addressed: characterization of ring-wave frequency spectra as a function of $R$ and the functional form of backscattered signal probability-density-distribution as a function of $\mathrm{R}$. 


\section{Background}

Case studies show that rain effects data from altimeters, scatterometers and SAR's (Guymer et al. 1981, Fu and Holt 1982, Hawkins and Black 1983, and Black et al. 1985, Srokosz and Guymer 1988) and that atmospheric corrections do not necessarily remove all biases (Black et al. 1985). So air-sea interaction processes need to be investigated. Laboratory data sets (Moore et al. 1979 and Bliven et al. 1989) indicate that (a) $\mathrm{Ku}$ - and Ka-band scatterometer backscattered power can be enhanced by water drops striking the air-water interface, and (b) that water surfaces agitated by solely light rains can yield about the same backscattered power as water surfaces roughened by solely light winds. Moreover, for combined light winds and light rains, Bliven and Giovanangeli (1992) established that backscattered power can be well modeled as the sum of rain and wind contributions. At higher winds and rain rates, various physical processes may be important. Attenuation of windwaves by rain-generated turbulence in the water has been measured by Tsimplis (1992), who found that estimates of eddy viscosity coefficients by Manton (1973) are too large by two orders of magnitude, so it is doubtful that wave-turbulence interaction is the dominant mechanism for wind-wave attenuation by rain. On the other hand, a model by Le Méhauté and Khangaonkar (1990) indicates that raindrop impacts on the water surface can be inhomogeneous and consequently, rain may contribute to long-wave growth. Gravity-wave interaction with capillary-waves has been modeled by Kharif et al. (1990), who report asymmetries as a function of the angle between the propagation directions of the two wavetrains. For application to in situ conditions, this model needs to be extended to include the effects of randomly distributed drop impacts. Consequently, surface agitation by rain needs to be included in empirical data inversion algorithms and numerical models-but data are certainly necessary to guide development and assessment of theoretical models.

Since the pioneering investigations by Wright (1966 and 1968) and Bass et al. (1968), estimates of radar backscattered power for viewing angles in the range of 30 to $60^{\circ}$ from nadir have been typically computed by representing the sea surface as a two-scale rough surface. The strengths and limitations of this formulation for wind-wave studies were reviewed by Plant (1990), who discusses that composite models are used to represent wind-roughened seas as patches of short waves (Bragg scattering model) that are locally tilted by large wave components. There is considerable evidence that scatterometer measurements are highly correlated to wind friction velocity (Jones and Schroeder 1977, Li et al. 1989, Giovanangeli et al. 1991 and Bliven et al. 1992). There also is considerable evidence that short gravity and capillary waves are the dominant spectral region that supports the bulk of the momentum fluxes from the wind to the water surface (see Plant (1982) for a review and Geernaert et al. (1986) for a recent assessment). Both aircraft data obtained by Ross and Jones (1978) and SEASAT data analyzed by Glazman (1988) show that the effect of long waves on scatterometer average backscattered power is small. With a recognition of these factors, the entire wavenumber spectrum is not needed for first-order modeling of average quantities. Indeed, Keller et al. (1992) employed laboratory results to assess assumptions concerning physical processes used in scatterometer wind-retrieval algorithms developed for field applications. Data from long fetches in wide wind-wave tanks can assist in development of application algorithms for combined wind and rain conditions. 
The Bragg scattering theory should be useful for modeling scattering from ring-waves. For example, scattering features generated by a single drop impacting a calm water surface were investigated by Wetzel (1990), who concludes that due to its small amplitude, "a perturbation approximation may legitimately be applied at microwave frequencies," and who uses Wright's (1966) model to effectively replicate backscattered power time series trom a ring-wave. Although Bragg scattering of microwaves from short wind-waves is widely used as the dominant mechanism in scatterometer wind algorithms and numerical models, the role of Bragg scattering from ring-waves has been quantified only for a restricted set of conditions by Bliven et al.(1993). A complete survey of rain effects on sea-surface processes is beyond the scope of this report, however, an extensive list of references is provided in section 8 . Raingenerated cavities, stalks, and ring-waves need to be measured simultaneously with microwave measurements in order to evaluate the role of these features.

\section{RSIF description and experimental conditions}

The Rain-Sea Interaction Facility at WFF was created during the summer of 1993 in order to make measurements of microwave scattering from water surfaces agitated by artificial rain. The purpose of this facility is to provide a controlled environment to study rain effects on microwave scattering from water surfaces and to use this data to develop and improve remote sensing algorithms. The aircraft hangar known as building N159 (Figure 3.1) contains a tower that was originally used for drying parachutes. Its dimensions are $4 \times 4 \times 17$ $\mathrm{m}$ and there is a water drain located in the center of the floor. A ladder in one corner leads to the high cat-walk platform at $14 \mathrm{~m}$. This area was ideally suited for conversion to the RainSea Interaction Facility.

We installed equipment at ground level for these studies as shown in Figure 3.2. The water tank $(2 \times 1 \times 1 \mathrm{~m})$ is centered above the drain and for operations it is filled to a depth of $80 \mathrm{~cm}$. Prior to each experiment, the tank is cleaned and filled with fresh water. A 6-cm hose is connected to the drain at the bottom of the tank and it is extended upward for use as a water overflow outlet, so that the water level is maintained at a constant height during experiments. The $13.5-\mathrm{GHz}$ and $36-\mathrm{GHz}$ scatterometer transmitter and receiver horns are pointing towards the center of the water tank. The storage shelves house the radar systems electronics, the capacitance probe electronics and a PC-based data acquisition system. The scatterometer systems are calibrated relative to the backscattered power from a $15-\mathrm{cm}$ metal sphere that is located at the operational range to the water surface $(1 \mathrm{~m})$. The water tank is empty during this calibration procedure. A capacitance wire-probe is used to measure water surface time-series in the tank at a point adjacent to the rain-simulator footprint. Data quality is assured by analyzing characteristics of each data set during each experiment. 
The high-capacity rain simulator (Figure 3.3) was built so that a broad range of rain rates could be simulated, especially extreme rainfalls. It consists of a stainless steel box ( $80 \mathrm{x}$ $80 \times 6 \mathrm{~cm}$ ) that has a water inlet and an air-vent that is open during filling-but closed during operation so that the system is sealed. A pump with volume control regulates the flow rate of filtered water to the rain simulator. The bottom of the box (Figure 3.4) contains 1100 holes spaced with $2.5 \mathrm{~cm}$ between center points. A plastic nipple is inserted into each hole and to these, various sized hypodermic needles can be attached from the exterior. Water drops with diameters ranging from 1.2 to $4.2 \mathrm{~mm}$ diameter are produced by using various sized needles. The rain simulator is centered above the water tank and it can be lifted and attached to the cat-walk by means of a 500-lb-capacity winch that is attached to the cat-walk.

For this investigation, analog signals from the radars and capacitance probe were digitized at $256 \mathrm{~Hz}$ for $128 \mathrm{~s}$ to obtain $32 \mathrm{k}$ of data for each experimental condition.

\section{NCS versus R: Square-root model}

Radar time-series of backscattered power measurements from the water surface roughened by $2.8-\mathrm{mm}$ diameter drops falling from $1 \mathrm{~m}$ are shown in Figure 4.1 . The relative power RP values are normalized by the return power level from the calibration sphere. For similar conditions, the backscattered power levels are usually lower for the $36-\mathrm{GHz}$ system than for the 13.5- GHz system.

Average backscattered power levels NCS have been computed from the times-series data and a typical summary figure for the 13.5 -and $36-\mathrm{GHz}$ scatterometers is shown as a function of $\mathrm{R}$ for rain rates up to $200 \mathrm{~mm} \mathrm{hr}^{-1}$ in Figure 4.2. These results were obtained using 2.8-mm-diameter drops falling from $1 \mathrm{~m}$. To gain experience and develop techniques, we conducted numerous experiments with the rain simulator at $1 \mathrm{~m}$ from the calm water surface. One data set was obtained with the simulator at $13 \mathrm{~m}$, but that series was terminated in order to make modifications to the simulator when a seal suddenly burst. Analysis of the data from $1 \mathrm{~m}$ show trends that are similar to those from the data from $13 \mathrm{~m}$. Certainly investigation of drop-size and fall velocity effects are appropriate and will be conducted in the future-but much can be gained from analyzing the 1-m data and we present those results which are a guide to future studies. For the square-root model, a small DC-offset has been removed to force the model to zero when there is no rain. The data are well described by a square-root function, as shown in Figure 4.2 for 2.8 -mm-diameter drops falling from $1 \mathrm{~m}$.

At light rainfall rates, the square-root relationship is similar to a linear model-but at higher rainfall rates, the relative increase of NCS with R decreases so a linear model is not appropriate. For the entire range of simulated rains, a square-root model represents the Kuand $\mathrm{Ka}$-band data obtained with the rain simulator (2.8-and $4.2-\mathrm{mm}$-diameter drops) at $1 \mathrm{~m}$ from the water surface very well. Preliminary results with the rain simulator $(2.8-\mathrm{mm}$ drops) at $13 \mathrm{~m}$ exhibit a similar trend. It is interesting to observe that at high rainfall rates, NCS continues to increase as $R$ increases-i.e., there is no evidence of saturation. Thus all of these data from an extended range of rainfalls indicate that a square-root relationship between NCS and $\mathrm{R}$ is fitting. 


\section{Ring-wave spectra: Log-Gaussian model}

To obtain a quantitative measurement of the rain-roughened water surface, we used a capacitance probe to measure surface elevation time-series at a point adjacent to the rain simulator footprint. A typical time series is shown in Figure 5.1 which indicates that although the ring-waves are small (typically less than $1 \mathrm{~mm}$ in height), the measurement is not noisy.

A similar arrangement was used by Bliven et al. (1993b), however, that rain simulator (also about $75 \times 75 \mathrm{~cm}^{2}$ ) contained only 72 nozzles and the capacitance probe was located exceedingly close to the impact point of drops from one of the nozzles. As a result, the surface elevation frequency-spectra contained features related to the drop impact-rate (number of drops per second striking the surface) as well as the more random ring-waves from the other 71 nozzles. Unfortunately even light rains required a drop production rate for each nozzle that was higher than $2 \mathrm{~Hz}$ so the two spectral features are not easily separable-thus interpretation of those data is hampered. One of the design specifications for the new rain simulator at RSIF was that rainfall rates up to $200 \mathrm{~mm} \mathrm{hr}^{-1}$ be feasible with 2.8 -mm-diameter drops at an average production rate less than $2 \mathrm{~Hz}$ from the nozzles. This specification facilities the unambiguous identification of ring-wave components in surface-elevation frequency spectra.

Typical ring-wave frequency spectra are displayed in Figure 5.2, from which it is apparent that the peak frequency is about $6.5 \mathrm{~Hz}$, the bandwidth is quite narrow and the decay is asymmetric - faster decay on the low-frequency side than on the high-frequency tail.

We model these spectral features by using a logarithmic gaussian relationship given by:

$$
S_{f}(f)=S_{f_{p}} \exp \left\{-\pi\left[\frac{\ln \left(\frac{f}{f_{p}}\right)}{\frac{\Delta f}{f_{p}}}\right]^{2}\right\}
$$

where:

$$
\begin{aligned}
& S_{\mathrm{fp}} \quad \text { : spectral peak magnitude. } \\
& \mathrm{f}_{\mathrm{p}} \quad \text { : peak frequency. } \\
& \Delta \mathrm{f} \quad \text { : frequency bandwidth. }
\end{aligned}
$$


These three parameters can be obtained from the data by a least-square algorithm, examples of the close agreement between the model and the spectral data are shown in Figure 5.2. This analysis has been done for all the rainfall-rates and the results are shown in Figure 5.3, which shows that the spectral peak frequency is a weak function of rainfall-rate and the spectral bandwidth is approximately constant. The 3-dB bandwidth and the bandwidth parameter $\Delta f$ are related by

$$
\Delta f_{3 d B}=2 f_{p} \sinh \left[\frac{\Delta f}{f_{p}} \sqrt{\frac{\ln (2)}{\pi}}\right]
$$

In spite of that complicated relationship between $\Delta f$ and $\Delta f_{3 \mathrm{~B}}$, they are approximately equal ( $\Delta \mathrm{f}$ is $\sim 5 \%$ greater than the $3-\mathrm{dB}$ bandwidth). Thus another feature of this model is that $\Delta \mathrm{f} . \mathrm{S}_{\mathrm{fp}}$ contains more than $90 \%$ of the total energy, so a close approximation of the elevation variance can be estimated from two of the characteristic parameters, i.e.

$$
\zeta_{m}^{2}=\int_{1 \mathrm{~Hz}}^{16 \mathrm{~Hz}} S_{f}(f) d f \simeq S_{f_{p}} \Delta f
$$

where the subscript $m$ means relative to the model. 
Wavenumber elevation spectra can be obtained from frequency spectra by using an appropriate dispersion relationship which depends upon the fluid properties and wave characteristics. For gravity-capillary waves, a commonly used dispersion relationship is

$$
\sigma^{2}=g k+\frac{\tau}{\rho} k^{3}
$$

where:

$$
\begin{array}{lll}
\mathbf{k} & : \text { wavenumber spectrum } & \left(\mathrm{cm}^{-1}\right) \\
\sigma=2 \pi \mathrm{f} & : \text { radian frequency } & (\mathrm{rd} \mathrm{s}) \\
\mathrm{g} & : \text { gravitational constant } & \left(980 \mathrm{~cm} \mathrm{~s}^{-2}\right) \\
\rho & : \text { water density } & \left(1 \mathrm{~g} \mathrm{~cm}^{-3}\right) \\
\tau & : \text { water surface tension } & \left(\sim 74 \text { dynes cm } \mathrm{cm}^{-1}\right)
\end{array}
$$

The change of variables between frequency space and wavenumber space is accomplished by using a dispersion relationship and the following formula

$$
S_{k}(k)=\frac{1}{2 \pi} S_{f}(f(k)) \frac{d \sigma}{d k}
$$

where the derivative of radian frequency with respect to wavenumber is the phase speed V.

Using equation (4), the log-gaussian frequency spectral model can be expressed in wavenumber space as

$$
S_{k}(k)=\frac{1}{2 \pi} V(k) S_{f_{p}} \exp \left(-\pi\left[\frac{\log \left(\frac{\sqrt{g k+\frac{\tau}{p}} k^{3}}{2 \pi f_{p}}\right.}{\frac{\Delta f}{f_{p}}}\right]^{2}\right)
$$

Although this analytical wavenumber spectral model is derived directly from a simple frequency spectral model, it is cumbersome to use, particularly because the $k$ dependence appears in the amplitude factor $V(k)$. 
A simpler spectral model can be written as

$$
S_{k}(k)=S_{k_{p}} \exp \left(-\pi\left[\frac{\ln \left(\frac{k}{k_{p}}\right)}{\frac{\Delta k}{k_{p}}}\right]^{2}\right)
$$

with the coefficients given by

$$
\begin{gathered}
S_{k_{p}}=\frac{1}{2 \pi} V_{p} S_{f_{p}} \\
\left(2 \pi f_{p}\right)^{2}=g k_{p}+\frac{\tau}{\rho} k_{p}^{3}
\end{gathered}
$$

and

$$
\Delta k\left(r d \mathrm{Cm}^{-1}\right)=\frac{2 \pi}{V_{p}} \Delta f(H z)
$$

where $V_{p}$ is the phase speed at the peak frequency.

This simple model provides a good approximation of equation (6) for $k$ ranging from $0.04 \mathrm{rd} \mathrm{cm}^{-1}$ to $4.3 \mathrm{rd} \mathrm{cm}^{-1}$, i.e. it has a similar shape and represents $98 \%$ of the total energy. It is interesting to note that for these experimental data, $f_{p}$ is $\sim 6.4 \mathrm{~Hz}$ so $V_{p}$ is close to the minimum phase speed $V_{m}\left(17.83 \mathrm{~cm} \mathrm{~s}_{-1}\right)$ and $k_{p} \sim 1.43 \mathrm{rd} \mathrm{cm}^{-1}$, which is consistent with a model developed by Le Méhauté (1988) for individual drops and extended by Sobieski (1991) for natural conditions.

A typical surface elevation probability density distribution is shown in Figure 5.4, and analysis of all the surface elevation pd indicates that the distributions are close to Gaussian.

The elevation psd for $11.6 \mathrm{~Hz}$ was used to estimate the psd for the Bragg resonant wavelength for the 13.5-GHz scatterometer. These psd values are shown in Figure 5.5, and a square-root dependence on $\mathrm{R}$ represents the data well. We note that both the elevation variance and elevation psd at $11.6 \mathrm{~Hz}$ have trends which are consistent with the NCS squareroot vs $\mathrm{R}$ model. 


\section{RP probability density distributions: Erlang model}

The scatterometer RP time-series (r) are positive signals (Figure 6.1) and the probability density distributions look like the familiar Rayleigh distribution (Figure 6.2). Relative power RP values are normalized by the return power level from the calibration sphere. Each probability density distribution increases from zero to a maximum value and decrease toward zero as $r$ increases. Unfortunately a semi-logarithm plot shows that the decay is linear in log scale and not parabolic as it is for Rayleigh function. So the decay is exponential with respect to $r$ higher than the peak value in regular scale. The Rayleigh distribution is totally determined by a single parameter-either the mean value or the standard deviation - so it is impossible to independently adjust the magnitude of the peak and the decay rate.

The Erlang distribution is a two-parameter function so it can account for a linear decay in $\log$ scale and variable magnitude of the peak. The form of the Erlang distribution is

$$
\mathrm{E}_{\alpha, \lambda}(r)=\frac{\lambda^{(\alpha+1)}}{\Gamma(\alpha+1)} r^{\alpha} e^{-\lambda r}
$$

where:

$r$ : normalized radar data with respect to the sphere.

$\alpha$ : order of Erlang function.

$\lambda$ : exponential coefficient.

$\Gamma$ : Euler gamma function or generalized factorial function.

The first and second moments of the distribution, i.e. the mean $<r>$ and the standard deviation $\sigma_{r}$ are functions of the two Erlang's parameters.

mean value:

$$
\bar{r}=\frac{\alpha+1}{\lambda}
$$

standard deviation:

$$
\sigma_{r}=\frac{\sqrt{\alpha}+1}{\lambda}
$$

Likewise, a simple formula relates alpha and lambda to mean and standard deviation by inversion of the above equations.
Alpha parameter :
$\alpha=\left(\frac{\bar{r}}{\sigma_{f}}\right)^{2}-1$
Lambda parameter:

$$
\lambda=\frac{\bar{r}}{\sigma_{r}^{2}}
$$


The mean values and standard deviations of RP are well modeled by a square-root function over a broad range of rain-rates (10 to $210 \mathrm{~mm} \mathrm{hr}^{-1}$ ) as shown in Figure 6.2. A small DC offset has been removed from the square-root model to force the model to zero when there is no rain. From the RP data time-series, mean and standard deviation values were computed and used to model the measured PDs by the Erlang distribution. The close agreement with the observations is apparent in Figure 6.3.

For both radars, alpha is an increasing function. On the other hand, lambda is a decreasing function of rain-rate. This combination of parameters leads to the following observations. High-RP values ( 'big' features) have higher probability to occur as rainfall-rate increases, therefore rare events at light rain become common events at heavy rain.

\section{Summary}

The new Rain-Sea Interaction Facility has been established and the first finds are presented in this report. The unique feature of this laboratory is the ability to systematically study microwave scattering from a water surface roughened by artificial rain, for which the droplets are at terminal velocity. The laboratory instruments and systems such as the rain simulator were evaluated for functionality during these first experiments so the majority of the data were obtained with the rain simulator at $1 \mathrm{~m}$ above the water tank. The tests were successful, so future experiments will be able to use the rain simulator attached to the cat-walk at a height of $13 \mathrm{~m}$. Preliminary data from this evaluation period indicate that the data trends from $1 \mathrm{~m}$ do not change dramatically when the rain simulator is at the full height. Data are needed, however, to develop/validate scaling laws for non-terminal velocity conditions, which are typical for laboratory settings. The log-gaussian spectral model and the Erlang probability density distribution model should be able to represent data from a broad range of conditions, nonetheless, systematic studies need to be conducted to obtain parameter coefficients from configurations closer to natural conditions. Thus the results presented here are intended to illustrate the capability of the new Rain-Sea Interaction Facility and further investigations are planned to provide improved understanding of physical processes.

From these initial experiments, three new models have been proposed: the square-root function for NCS vs R, the log-gaussian model for ring-wave elevation frequency spectrum, and the Erlang probability density distribution for backscattered power. Rain rate is the main input for these models, although the coefficients may be dependent upon other factors (dropsize distribution and fall velocity). Thus further experiments are needed to refine the models.

Acknowledgements. NASA (RTOP 972-461-31-08) and Office of Naval Research (ONR 972146-70-11) contributed funding for this research. Jean P. Schermann of the Formation d'ingenieur en telecommunications, L'Université de Paris XIII, and Claude Klapisz of DEA de Methode physique en teledetection, L'Université de Paris VII helped coordinate and support this international collaboration. 


\section{References}

ATLAS, D. and MENEGHINI, R., 1983. Simultaneous ocean Cross-section and rainfall measurements from space with a nadir pointing radar. 21st Conf. on Radar Met., Edmonton, CA.

ATLAS, D. and THIELE. O. (eds.), 1981. Precipitation measurements from space. Workshop Report NASA/GSFC, $431 \mathrm{pp}$.

ATLAS, R., BUSALACCHI, A.J., GHIL, M., BLOOM, S., and KALNAY, E., 1987, Global surface winds and flux fields from model assimilation of Seasat data. Journal Geophysical Research, 92, 6477-6487.

BANNER, M. L., and MELVILLE, W.K., 1976, On the separation of air flow over water waves. Journal Fluid Mechanics, 77(4), 825-842.

BARRICK, D.E., 1972. Remote sensing of sea state by radar, Remote Sensing of the Troposphere, Ed. by V.E. Derr, U.S. Government Printing Office.

BARRICK, D.E. and LIPA, B.J., 1985. Analysis and interpretation of Altimeter Sea Echo, Satellite Oceanic Remote Sensing, Adv. in Geophysics, 27, 61-100.

BASS, F.G., FUKS, I.M., KALMYKOV, A.I., OSTROVSKY, I.E. and ROSENBERG, A.D., 1968, Very high frequency radiowave scattering by a disturbed sea surface. IEEE Transactions on Antennas and Propagation, AP-16, 560-568.

BLACK, P.G., GENTRY, R.C., CARDONE, V.J. and HAWKINS, J.D., 1985, Seasat microwave wind and rain observations in severe tropical and midlatitude marine storms. Advances in Geophysics, 27, 198-278.

BLIVEN, L.F. and NORCROSS, G., 1988, Effects of rainfall on scatterometer derived windspeeds. Proceedings of the IGARSS'88 held in Edinburgh, Scotland, on 12-16 September 1988, ESA SP-284 (Paris: European Space Agency), 1, 565-566.

BLIVEN, L.F., GIOVANANGELI, J-P. and NORCROSS, G., 1988, A study of rain effects on radar scattering from water waves. Proceedings of the $7^{t h}$ Conference on Ocean-Atmosphere Interactions of American Meteorological Society held in Anaheim, California, on 1-5 February 1988, Boston, MA: Am. Met. Society D(VT) 500 1/88, 230-233.

BLIVEN, L. and GIOVANANGELI, J-P., 1993, An experimental study of microwave scattering from rain- and wind-roughened seas. International Journal of Remote Sensing, 14(5), 855-869.

BLIVEN, L., GIOVANANGELI, J-P., WANNINKHOF, R.W. and CHAPRON, B., 1993a, A laboratory study of friction velocity estimates from scatterometry: low and high regimes. International Journal of Remote Sensing, 14(9), 1775-1785.

BLIVEN, L., BRANGER, H., SOBIESKI, P. and GIOVANANGELI, J-P., 1993b, An analysis of scatterometer returns from a water surface agitated by artificial rain, International Journal of Remote Sensing, in press.

BROWN, G.S., 1978. Backscattering from a Gaussian-distributed perfectly conducting rough surface, IEEE-Trans., AP-26, 472-482

BURROWS, C.R. and ATWOOD, S.S., 1949, Drop-size Distribution. In Radar Handbook, edited by M.I. Skolnik, (McGraw-Hill Book Company, New York, 1970), 24-24. 
CHELTON, D.B., MESTAS-NUNEZ, A.M., and FREILICH, M.H., 1990, Global wind stress and Sverdrup circulation from the Seasat scatterometer, Journal Physical Oceanography, 20, 1176-1205.

COANTIC, M. and FAVRE, A., 1974, Activities in and preliminary results of air- sea interaction research at IMST. Advances in Geophysics, 16, 391-405.

DUNCAN, J.R., KELLER, W.C. and WRIGHT, J.W., 1974, Fetch and wind speed dependence of Doppler spectra. Radio Science, 9, 809-819.

FEDOR, L.S. and BROWN, G.S., 1982. Waveheight and windspeed measurements from the SEASAT radar altimeter, $J G R, 87,3254-3260$.

FU, L. and HOLT, B., 1982, Seasat views oceans and sea ice with synthetic-aperture radar. NASA-JPL pub 81-120, 200.

GEERNAERT, G.L. KATSAROS, K.B. and RICHTER, K., 1986, Variations of the drag coefficient and its dependence on sea state, Journal of Geophysical Research, 91(C6), 7667-7679.

GOLDHIRSH, J., 1982. Slant path fade and rain-rate statistics associated with the COMSTAR beacon at $28.56 \mathrm{GHz}$ for Wallops Island, IEEE Trans on antennas and propagation, AP-30(2), 191-198.

GEERNAERT, G.L., 1990, Bulk parameterizations for the wind stress and heat fluxes. In Surface Waves and Fluxes, edited by G.L. Geernaert and W.J. Plant (Amsterdam: Kluwer Academic Publishers), 1, 91-172.

GIOVANANGELI, J-P., 1980, A nondimensional heat transfer law for a slanted hot film in water flow. DISA Information, 12.

GIOVANANGELI, J., BLIVEN, L., LE CALVE, O., 1991, A wind-wave tank study of the azimuth response of a $\mathrm{K}_{\mathrm{a}}$-band scatterometer. IEEE Transactions on Geoscience and Remote Sensing, 29(1), 143-148, 1991.

GLAZMAN, R.E., PIHOS, G.B. and IP, J., 1988, Scatterometer wind-speed bias induced by the large-scale component of the wave field. Journal of Geophysical Research, 93, 1317-1328.

GUISSARD, A., BAUFAYS, C. and SOBIESKI, P., 1993, Fully and non-fully developed sea models for microwave remote sensing applications, Remote Sensing of the Environment, in press.

GUISSARD, A., 1993, Directional spectrum of the sea surface and wind scatterometry, International Journal of Remote Sensing, in press.

GUNN, R. and KINZER, G.D., 1949, The terminal velocities of fall for water droplets in stagnant air. Journal of Meteorology, 6, 243-248.

GUINARD, N.W., RANSONE, J.T., JR., and DALEY, J.C., 1971, Variation of the NRCS of the sea with increasing roughness, Journal Geophysical Research, 76, 1525-1533.

GUYMER, T.H., BUSINGER, J.A., JONES, W.L. and STEWART, R.H., 1981, Anomalous wind estimates from the Seasat scatterometer. Nature, 294, 735-737.

HALLETT, J. and CHRISTENSEN, L., 1984, Splash and penetration of drops in water. Journal de Researches Atmosphériques, 18, 225-242.

HANSEN, J.P., 1984, High resolution radar backscatter from a rain disturbed sea surface. ISNR-84 Record, Symposium held in Tokyo, Japan, on 22-24 October, 1984. 
HANSEN, J.P., 1986, A system for performing ultra high resolution backscatter measurements of splashes. Proceedings of the International Microwave Theory and Techniques Symposium, l.E.E.E., New York.

HAWKINS, J.D. and BLACK, P.G., 1983, SEASAT scatterometer detection of gale force winds near tropical cyclones. Journal of Geophysical Research, 88(C3), 1674-1682.

KELLER, W.C. and PLANT, W.J., 1992, A wave tank study of the dependence of X-band cross sections on wind speed and water temperature. Journal of Geophysical Research, 97(C4), 5771-5792.

INOMATA, H., et al., 1981. Remote sensing of rainfall rates using airborne microwave rainscatterometer/radiometer. Proc. 15th Int. Symp. on Remote Sensing of Envir., Ann Arbor, Mich.

JACKSON, F.C., 1979. The reflection of impulses from a nonlinear random sea, J. Geophys. Res., 84, 4939-4943.

JONES, L.W. and SCHROEDER, L.C., 1977, Radar Backscatter From the Ocean Dependence on Surface Friction Velocity. Boundary-Layer Meteorology, 13, 133-149.

KATSAROS, K. and BUETTNER, K.J.K., 1969. Influence of rainfall on temperature and salinity of the ocean surface, J. of Appl. Met., 8, no.1, 15-18.

KHARIF, C., GIOVANANGELI, J-P., and BLIVEN, L.F., 1989, Rain waves-wind waves interaction and application to scatterometry. Proceedings of IGARSS'89 held in Vancouver, Canada, on 13-16 July 1989, ESA SP-284 (Paris: European Space Agency), 3, 1891-1896.

LE MEHAUTE, B., WANG, S. and LU, C.C., 1987, Spikes, domes, and cavities. Journal International Association of Hydraulic Research, 5, 583-602.

LARGE, W.G., POND, S., 1981, Open ocean momentum flux measurements in moderate to strong winds. Journal Physical Oceanography, 11, 324-336.

LE MEHAUTE, B., 1988, Gravity-capillary rings generated by water drops. Journal Fluid Mechanics, 197, 415-427.

LE MEHAUTE, B., 1988, Gravity-capillary rings generated by water drops. Journal of Fluid Mechanics, 197, 415-427.

LE MEHAUTE, B. and KHANGAONKAR, T., 1990, Dynamic interaction of intense rain with water waves. Journal of Physical Oceanography, 20, 1805-1812.

LI, F., LARGE, W., SHAW W., WALSH, E.J. and DAVIDSON, K., 1989, Ocean radar backscatter relationship with near-surface winds: a case study during FASINEX. Journal of Physical Oceanography, 19, 342-353.

LIU, W.T. and LARGE, W.G., 1981, Determination of surface stress by Seasat-SASS: a case study with JASIN data. Journal Physical Oceanography, 11, 1603-1611.

MANTON, M.J., 1973, On the attenuation of sea waves by rain. Journal of Geophysical Fluid Dynamics, 5, 249-260.

MELVILLE, W.K., 1977, Wind stress and roughness length over breaking waves. Journal of Physical Oceanography, 7, 702-710.

MENEGHINI, R. and ATLAS, D., 1986. Simultaneous ocean cross section and rainfall measurements from space with a nadir-looking radar. J Atmo and Oc Technology, 3, 400-413. 
MENEGHINI, R., ECKERMAN, J. and ATLAS, D., 1983. Determination of rain rate from a spaceborne radar using measurements of total attenuation. IEEE Trans Geos and Remote Sens., GE-21(1), 34-43.

MOORE, R.K., CHAUDHRY, A.H. and BIRRER, I.J., 1981 Errors in spaceborne scatterometer/radiometer ocean wind measurements due to rain that partially fills measurement area, NASA Langley Contract NSG 1397, 1-37.

MOORE, R. K. and FUNG A. K., 1979, Radar determination of winds at sea. Proceedings of the IEEE., 67(11), 1504-1521.

MOORE, R.K., YU, Y.S., FUNG, A.K., KANEKO, D., DOME, G.J., and WERP, R.E., 1979, Preliminary study of rain effects on radar scattering from water surfaces. I.E.E.E. Journal of Oceanographic Engineering, OE-4(1), 31-32.

MOORE, R.K., BIRRER, I.J., BRACALENTE, E.M., DOME, G.J., and WENTZ, F.J., 1982, Evaluation of atmospheric attenuation from SMMR brightness temperature for the Seasat satellite scatterometer. Journal of Geophysical Research, 95(C10), 3337-3354.

NYSTUEN, J.A., 1990, A note on the attenuation of surface gravity waves by rainfall. International Journal of Geophysical Research, 95(C10), 18353-18355.

PLANT, W.J., 1982, A relationship between wind stress and wave slope, Journal of Geophysical Research, 87(C3), 1961-1967.

PLANT, W.J., 1990, Bragg scattering of electromagnetic waves from the air/sea interface. in Surface Waves an Fluxes, edited by G.L. Geernaert and WJ. Plant (Amsterdam:Kluwer Academic Publishers), 2, 41-108.

POITEVIN, J., KHARIF, C. and RAMAMONJIARISOA, A., 1990. Effects of nonlinear wave dynamics on the microwave specular scattering from the sea surface, IEEE-IGARSS, Washington, DC.

RAO, M.S.V., ABBOTT, W.V., THEON, J.S., 1976. Satellite-derived global oceanic rainfall atlas, NASA X-911-76-116

REYNOLDS, O. 1875 , On the action of rain to calm the sea. Proceedings of the Literary Philosophical Society of Manchester, XIV, 72-74.

ROSS, D.B., 1981, The wind speed dependency of ocean microwave backscatter, In Spaceborne Synthetic aperture radar for oceanography, edited by Beal, R.C., DeLeonibus, P.S., and Katz, I. (Baltimore, MD: The Jonhs Hopkins University Press), 75-84.

ROSS, D. and JONES, W.L., 1978, On the relationship of radar backscatter to wind speed and fetch, Boundary Layer Meteorology, 13, 151-164.

SCHROEDER, L.C., BOGGS, D.H., DORNE, G., HALBERSTRAM, I.M., JONES, L.W., PIERSON, W.J. and WENTZ, F.J., 1982, The relationship between wind vector and normalized radar cross section used to derive Seasat A satellite scatterometer winds. Journal Geophysical Research, 87(C5), 3318-3336.

SIMPSON, J. (editor), 1988, Report of the science steering group for a Tropical Rainfall Measuring Mission (TRMM). NASA, 1-94.

SOBIESKI, P., GUISSARD, A. and BAUFAYS, C., 1991, Synergic inversion technique for active and passive microwave remote sensing of the ocean. IEEE Transactions on Geoscience and Remote Sensing, 29(3), 391-406. 
SOBIESKI, P., GUISSARD, A. and BAUFAYS, C., 1993, Comparison of microwave signatures for fully and non-fully developed sea modes, Remote Sensing of the Environment, in press.

SROKOSZ, M.A. and GUYMER, T.H., 1988, A study of the effect of rain on Seasat radar altimeter data. Proceedings of the IGARSS '88 Symposium held in Edinburgh, Scotland, on 13-16 September 1988, ESA SP-284 (Paris: European Space Agency), 651-654.

TSIMPLIS, M.N. and THORPE, S.A., 1989, Wave damping by rain, Nature, 342, 893-895.

TSIMPLIS, M.N., 1992, The effect of rain in calming the sea, Journal of Physical Oceanography, 22(4), 404-412.

ULABY, F.T., MOORE, R.K., and FUNG, A., 1982, Microwave Remote Sensing, II, (Reading, MA: Addison-Wesley).

WANNINKHOF, R.H. and BLIVEN, L.F., 1991, Relationship between gas exchange, wind speed, and radar backscatter in a large wind-wave tank, Journal of Geophysical Research, 96(C2), 2785-2796.

WEISSMAN, D.E., KING, D.B. and THOMPSON, T.W., 1979, Relationship between hurricane surface winds and L-band radar backscatter from the sea surface. Journal Applied Meteorology, 18, 1023-1034.

WETZEL, L.B., 1990, On the theory of electromagnetic scattering from a raindrop splash. Radio Science, 25(6), 1183-1197.

WILHEIT, T.T., CHANG, T.A., RAO, M.S.V., ROGERS, E.B. and Theon, J.S., 1977. A satellite technique for quantitatively mapping rainfall rates over the oceans, $J$. App. Met., 16, 551-560.

WOICESHYN, P.M., WURTELE, M.G., BOGGS, D.H., MCGOLDRICK L.F., and PETEHERYCH, S., 1986, The necessity for a new parameterization of an empirical model for wind/ocean scatterometry. Journal Geophysical Research, 91(C2), 22732288.

WORTHINGTON, A.M., 1882, A study of splashes. Proceedings of the Royal Society of London, 34, 217-229

WRIGHT, J.W., 1966, Backscatter from capillary waves with application to sea clutter. IEEE Transactions on Antennas and Propagation, AP-14, 749-754.

WRIGHT, J.W., 1968, A new model for sea clutter. IEEE Transactions on Antennas and Propagation, AP-16, 217-223.

WU, J., 1969a, Wind stress and surface roughness at air-sea interface. Journal Geophysical Research, 74(2), 444-454.

WU, J., 1969b, A criterion for determining air-flow separation from wind waves. Tellus, 21, 707-713.

WU, J., 1980, Wind Stress Coefficients Over Sea Surface Near Neutral Conditions-A Revisit, Journal of Physical Oceanography, 10(5), 727-740.

WU, J., 1986, Roughness elements of the sea surface-their spectral composition. Tellus, 38A, 178-188.

ULABY, F.T., MOORE, K.M., and FUNG, A., 1982, Microwave remote sensing, II, (AddisonWesley Publishing Company).(1) 


\section{Figures}

Figure 1. Rain-Sea Interaction Facility (17 $\mathrm{m}$ white tower).

Figure 2 Radar and tank.

Figure 3. Rain simulator $\quad 19$

Figure 4. Rain simulator nozzles.

Figure 4.1. Radar time series (a) $13.5 \mathrm{GHz}$ and (b) $36 \mathrm{GHz}$.

Figure 4.2 Square-root function for NCS vs rain rate.

Figure 5.1 Elevation time series.

Figure 5.2 Elevation spectra: log-Gaussian model.

Figure 5.3 Spectral Parameters: (a) Square-root model for e2 vs R,

Figure 5.4 Elevation pdf: Gaussian distribution.

Figure 5.5 Elevation variance at $11.5 \mathrm{~Hz}$.

Figure 6.1 Radar time series (a) $13.5 \mathrm{GHz}$ and (b) $36 \mathrm{GHz}$.

Figure 6.213 .5 and $36 \mathrm{GHz}$ radar statistics: (a) NCS vs R and (b) RP(std) vs R.

Figure 6.3 13.5 and $36 \mathrm{GHz}$ Radar PD distributions: Erlang Model.

Figure 6.4 Erlang function parameters for 13.5 and $36 \mathrm{GHz}$ radars:

(a) alpha and (b) lambda 


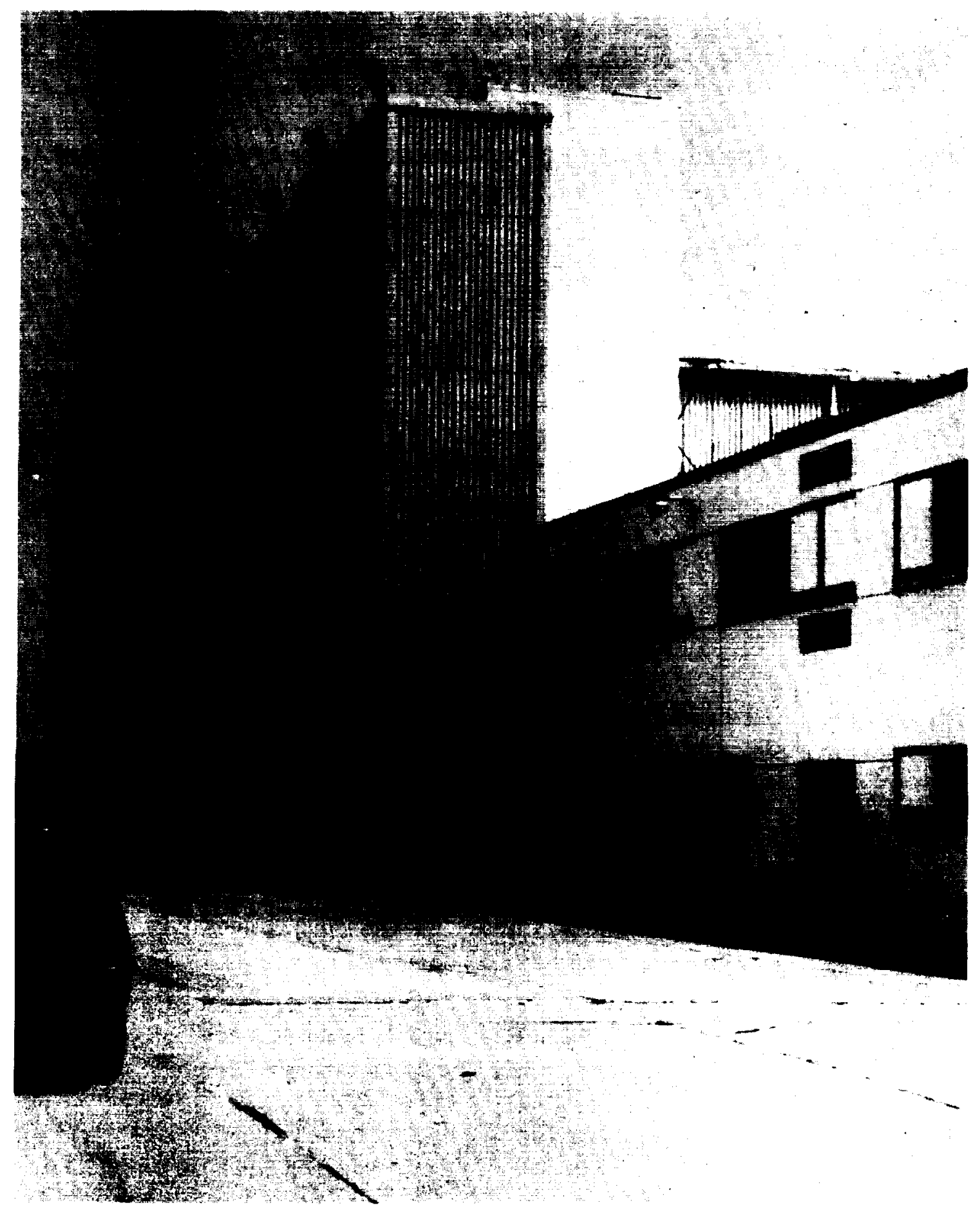

Figure 1. Rain-Sea Interaction Facility (17 m white tower). 


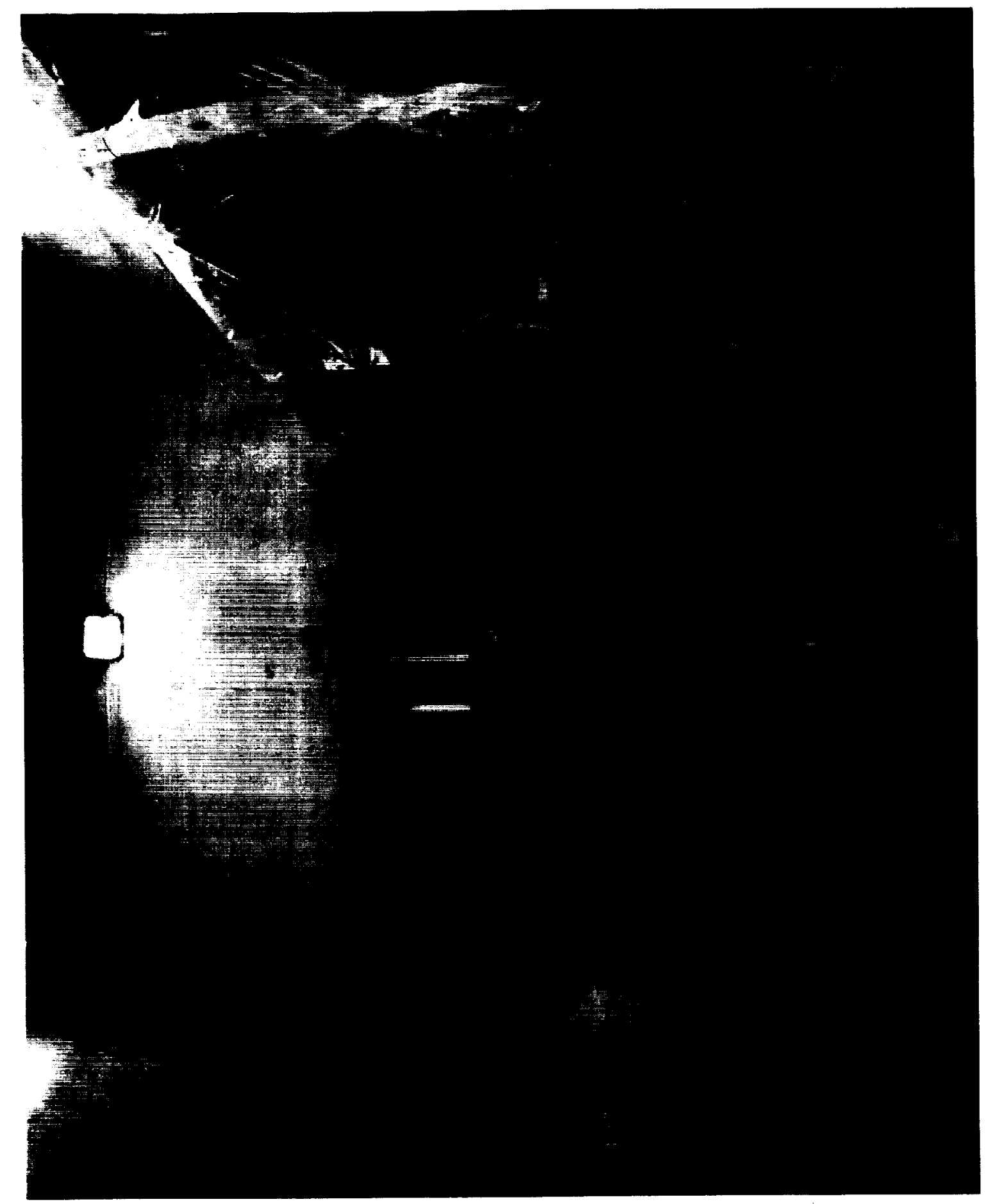

Figure 2. Interior of Rain-Sea Interaction Facility: Radars and Tank. 


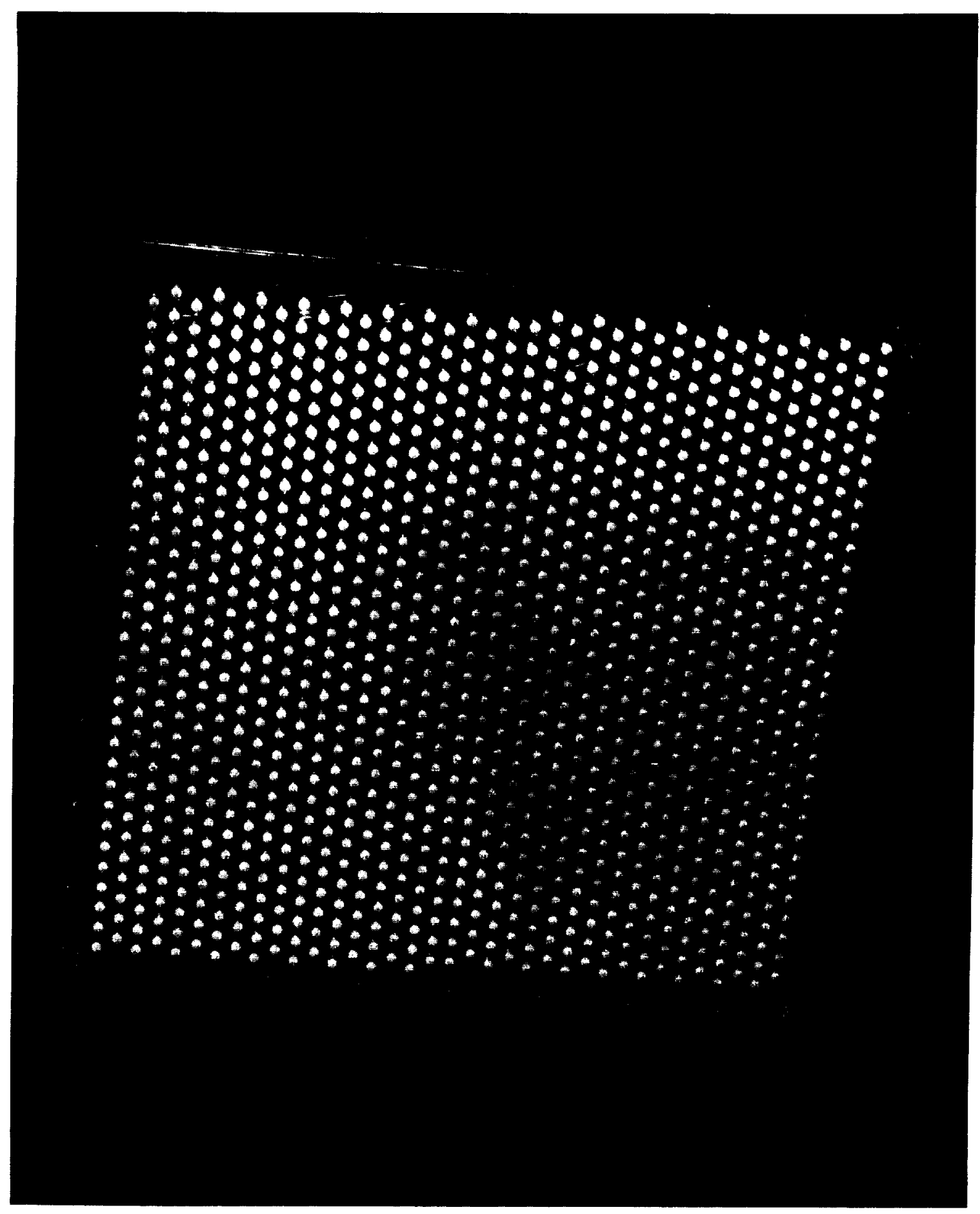

Figure 3. High Capacity Rain Simulator $(80 \times 80 \mathrm{~cm})$. 


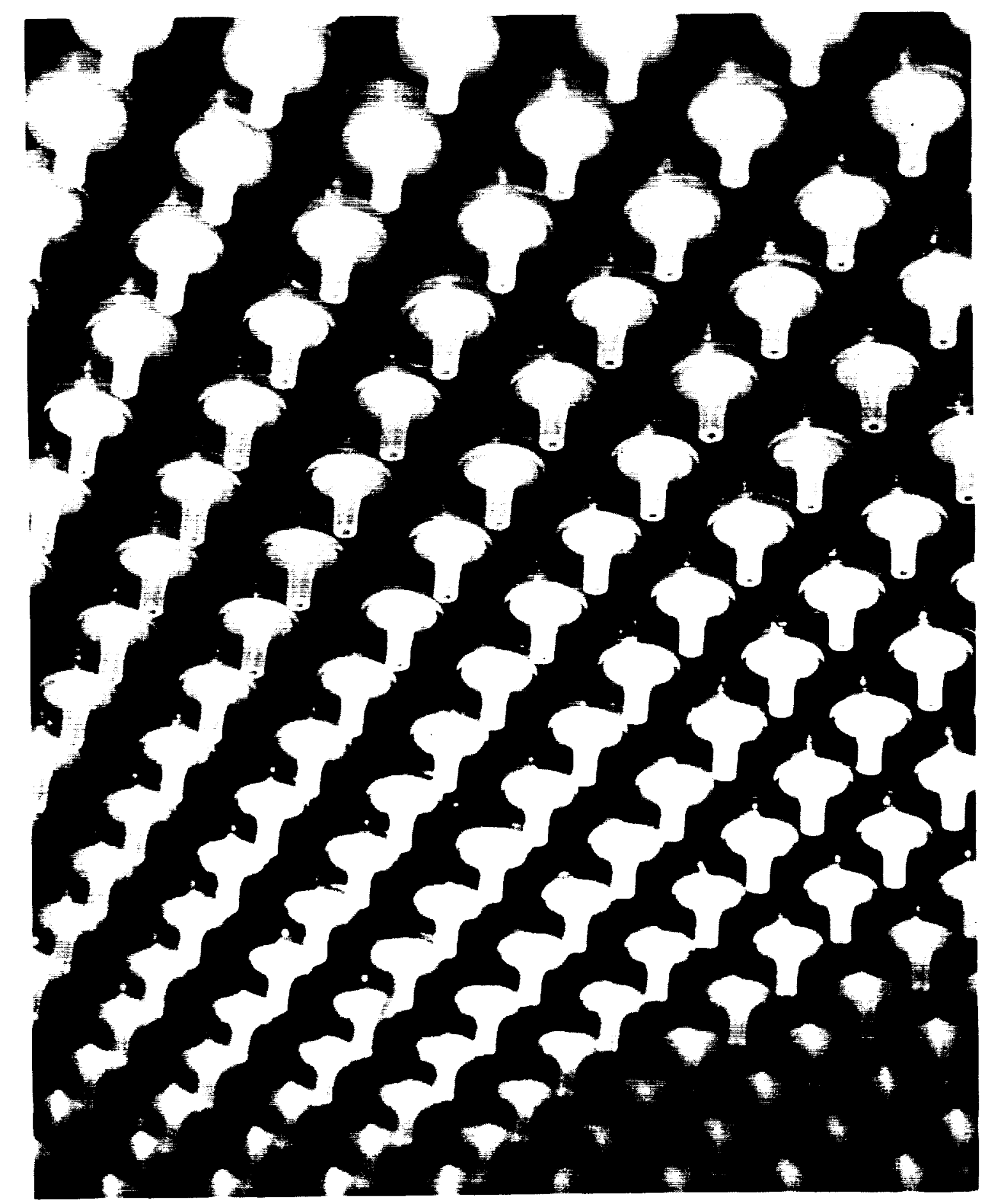

Figure 4. Rain-simulator detail -1100 nozzles with $2.54 \mathrm{~cm}$ center point spacing. 
13.5 GHz Scatterometer Time Series $2.8 \mathrm{~mm}$ diamoter drops, $1 \mathrm{~m}$ holght

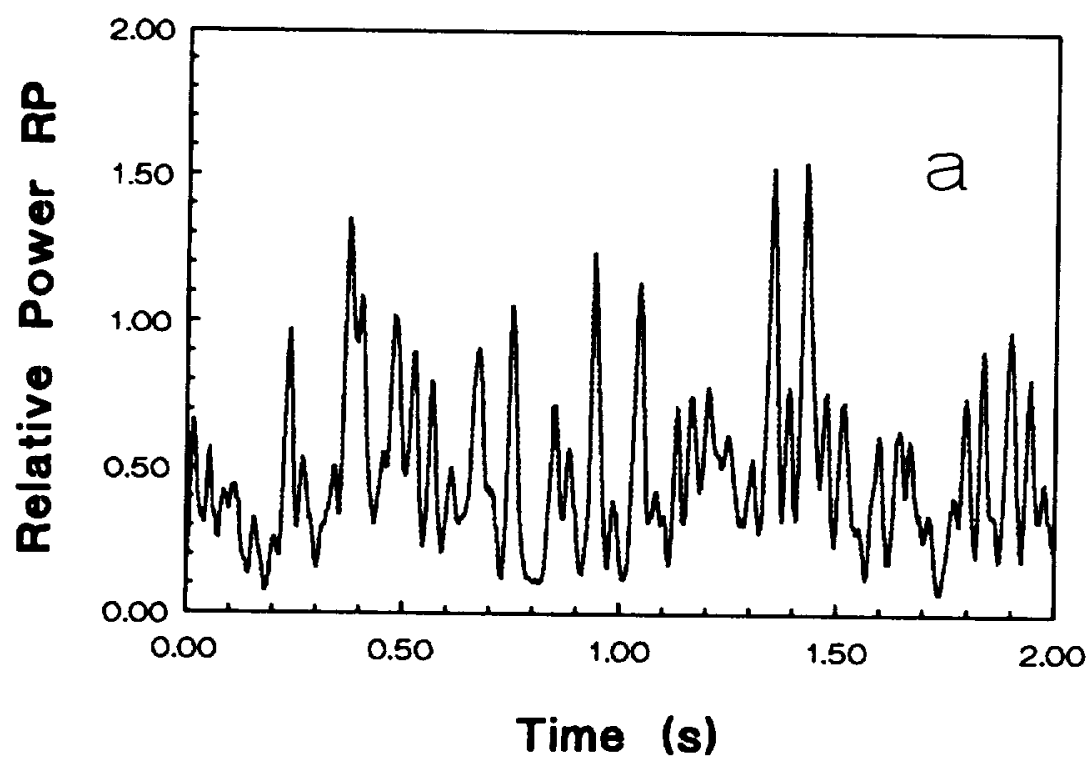

$36 \mathrm{GHz}$ Scatterometer Time Series $2.8 \mathrm{~mm}$ diameter drops, $1 \mathrm{~m}$ hoight

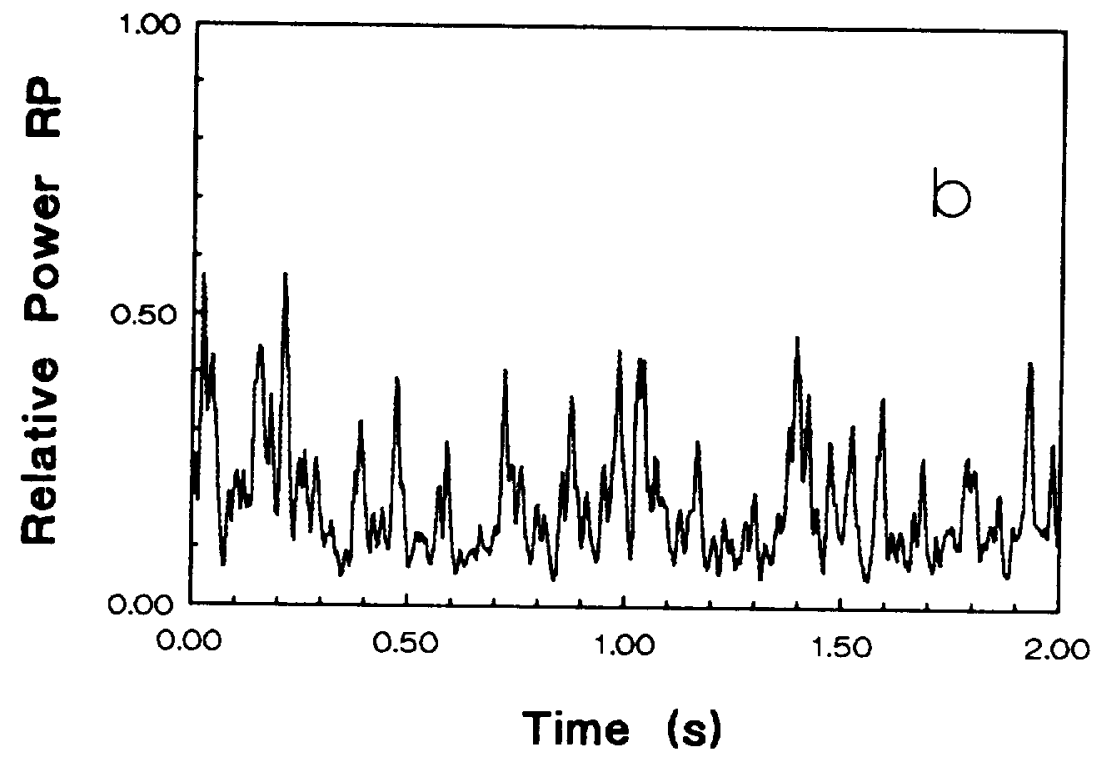

Figure 4.1. 


\section{Scatterometers}

$2.8 \mathrm{~mm}$ diameter drops, $1 \mathrm{~m}$ height

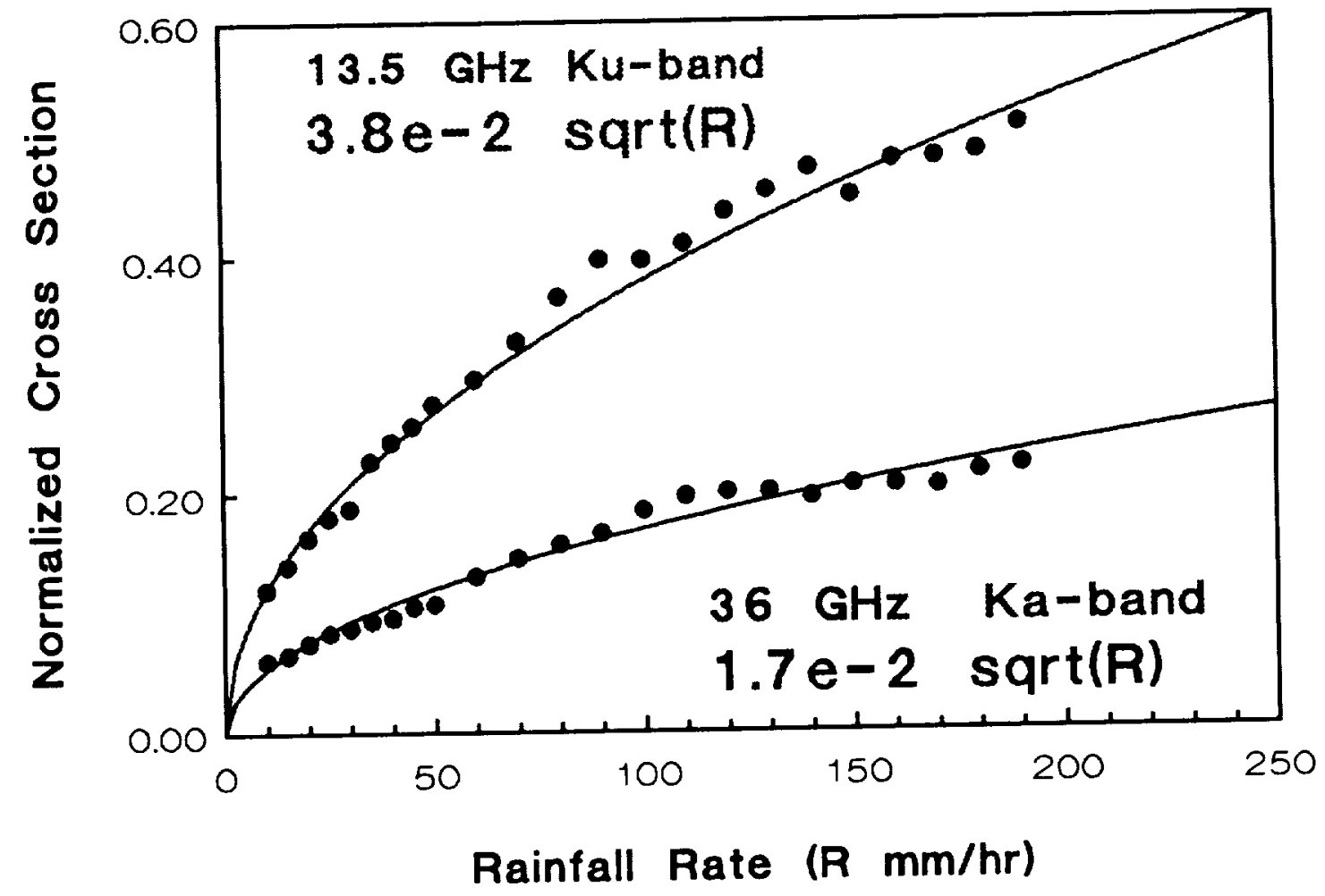

Figure 4.2. 


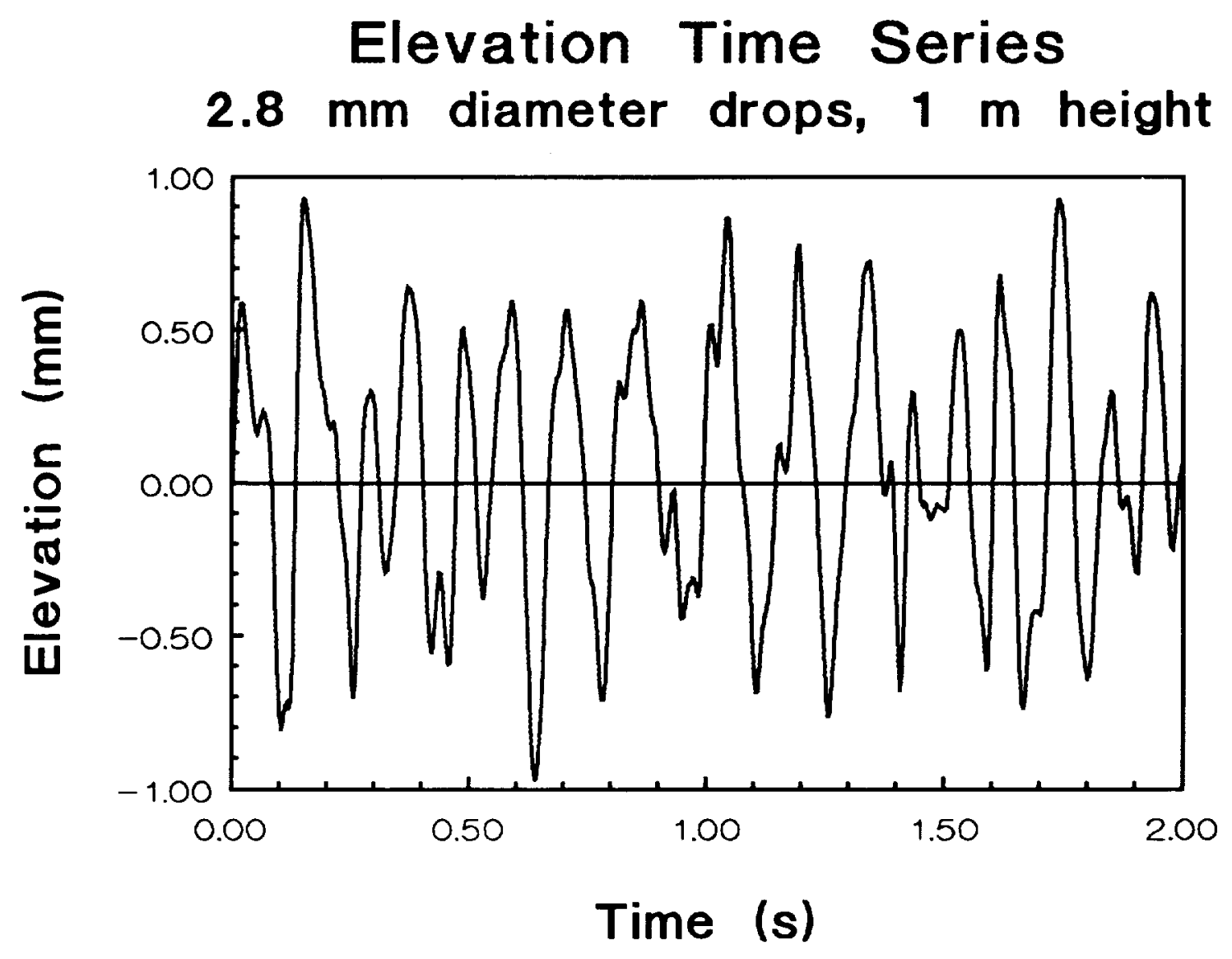

Figure 5.1. 
Elevation Spectra: Log-Gaussian Model

$2.8 \mathrm{~mm}$ diameter drops, $1 \mathrm{~m}$ height

+ $10 \mathrm{~mm} / \mathrm{hr}$ \& $42 \mathrm{~mm} / \mathrm{hr}$ - $110 \mathrm{~mm} / \mathrm{hr}$

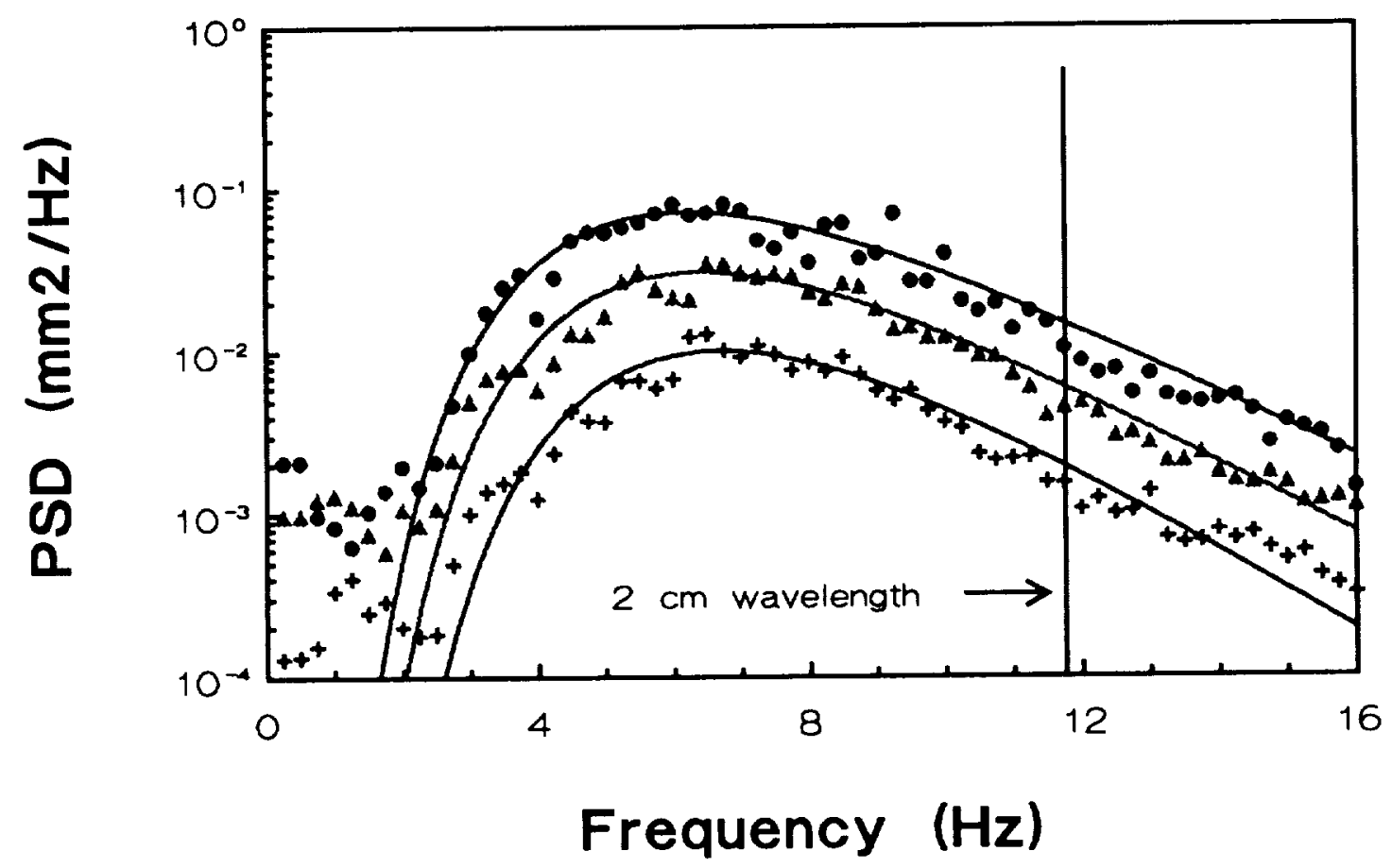

Figure 5.2. 

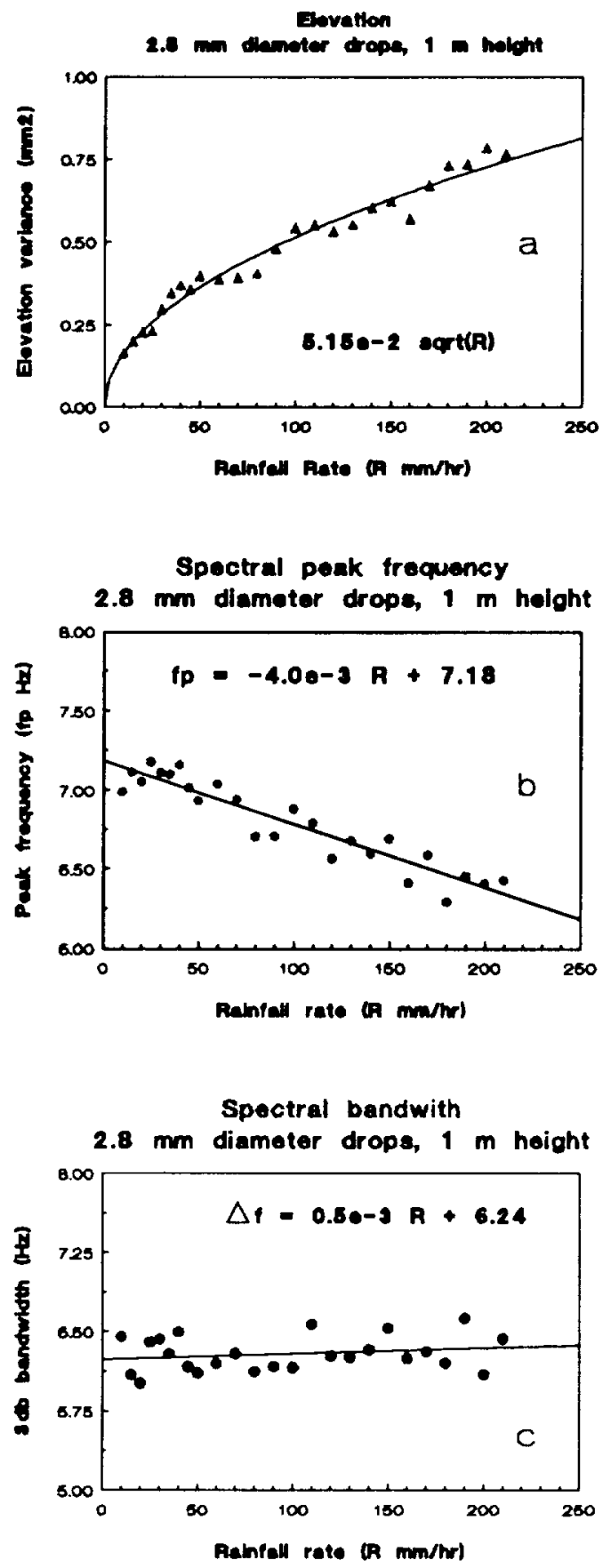

Figure 5.3. 
Elevation PD: Gaussian Model

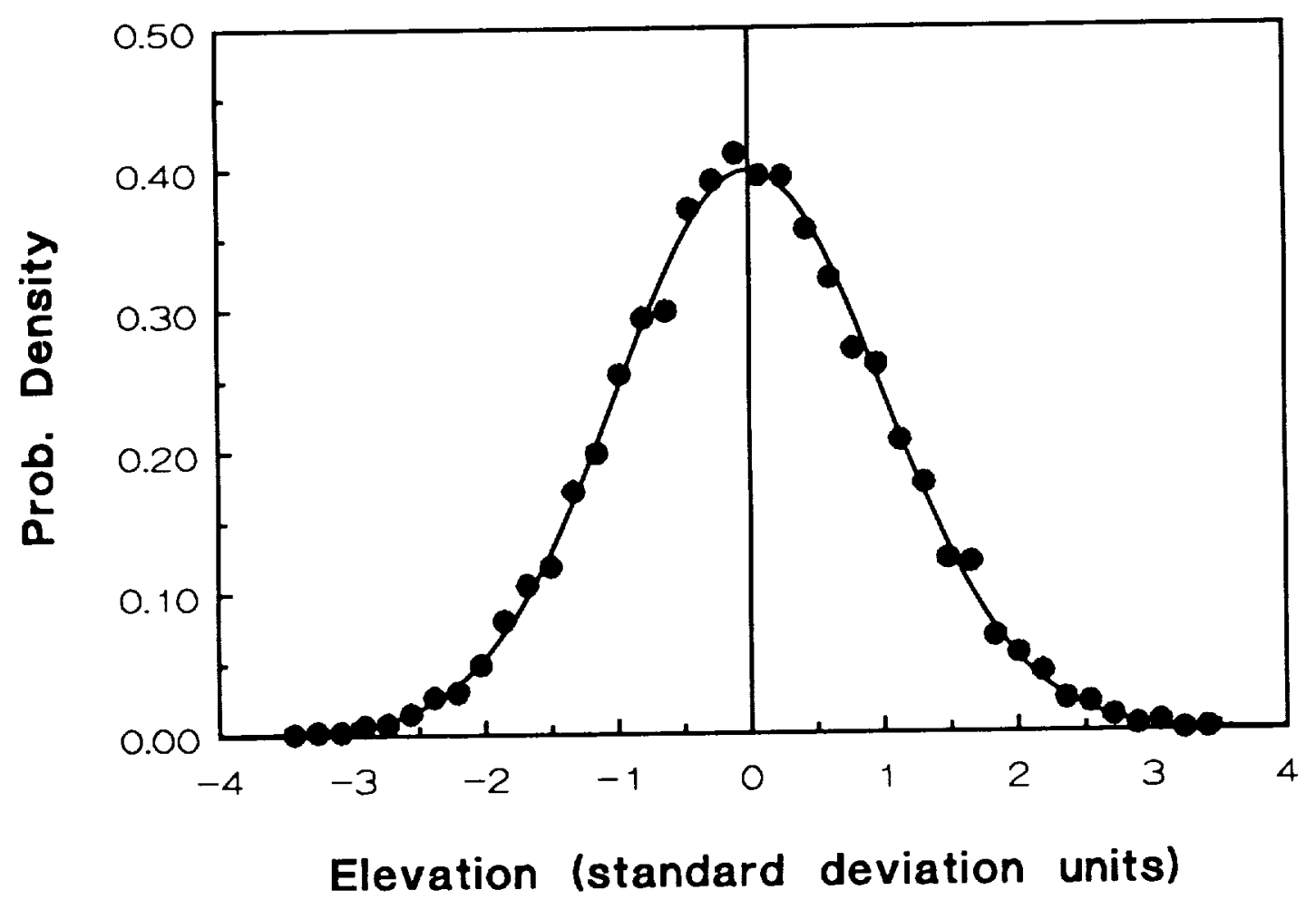

Figure 5.4. 
Elevation PSD at $11.6 \mathrm{~Hz}$

$2.8 \mathrm{~mm}$ diameter drops, $1 \mathrm{~m}$ height

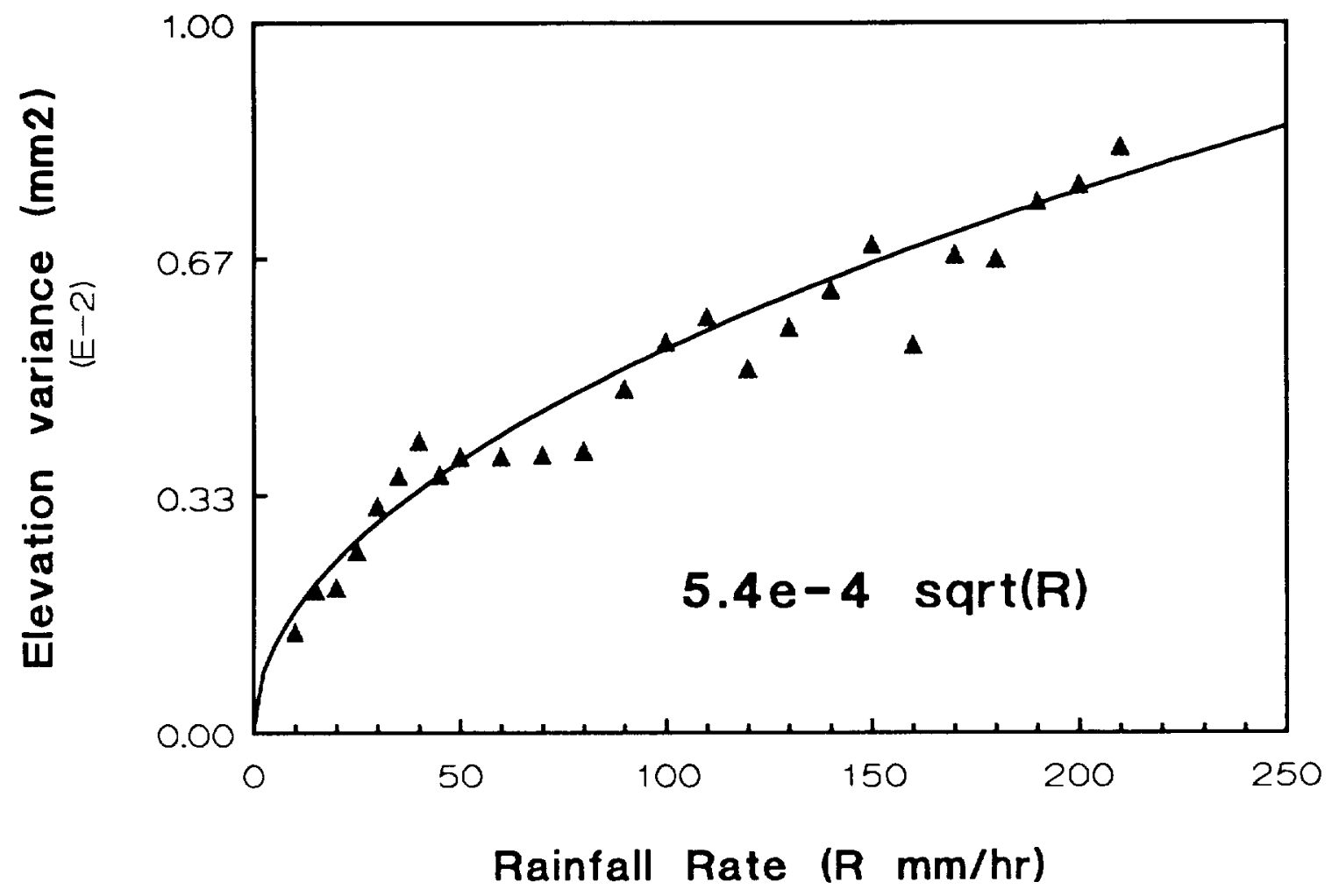

Figure 5.5. 
13.5 GHz Scatterometer Time Series $4.2 \mathrm{~mm}$ diameter drops, $1 \mathrm{~m}$ height

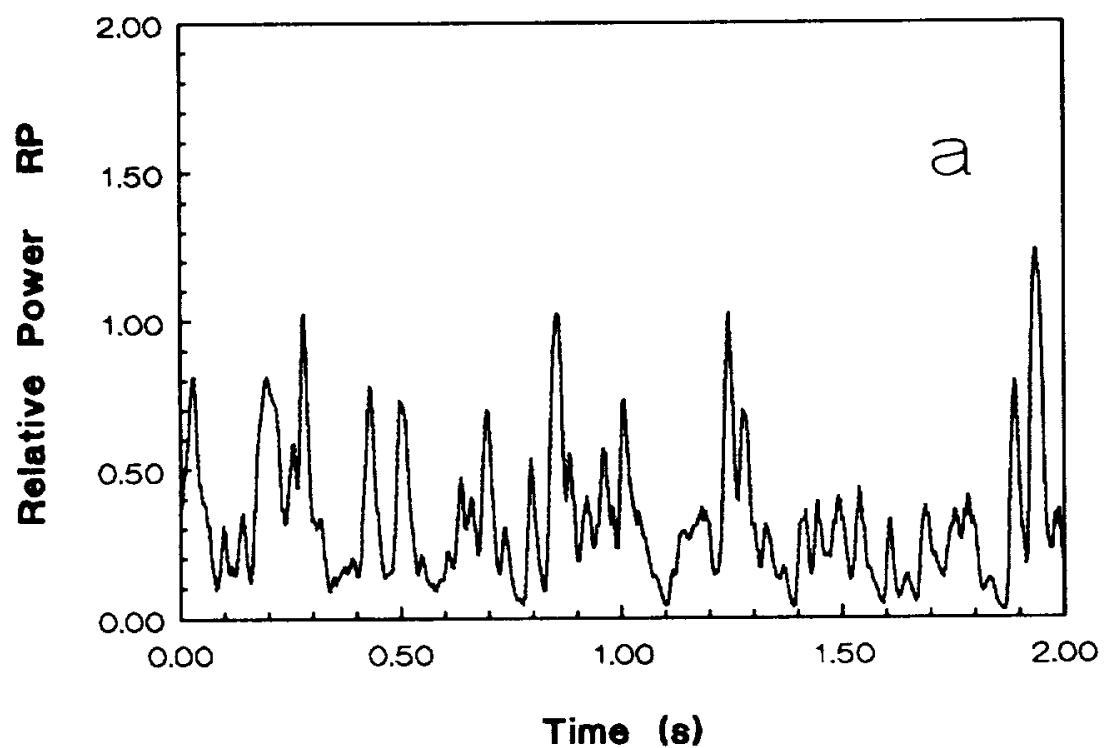

$36 \mathrm{GHz}$ Scatterometer Time Series $4.2 \mathrm{~mm}$ diameter drops, $1 \mathrm{~m}$ height

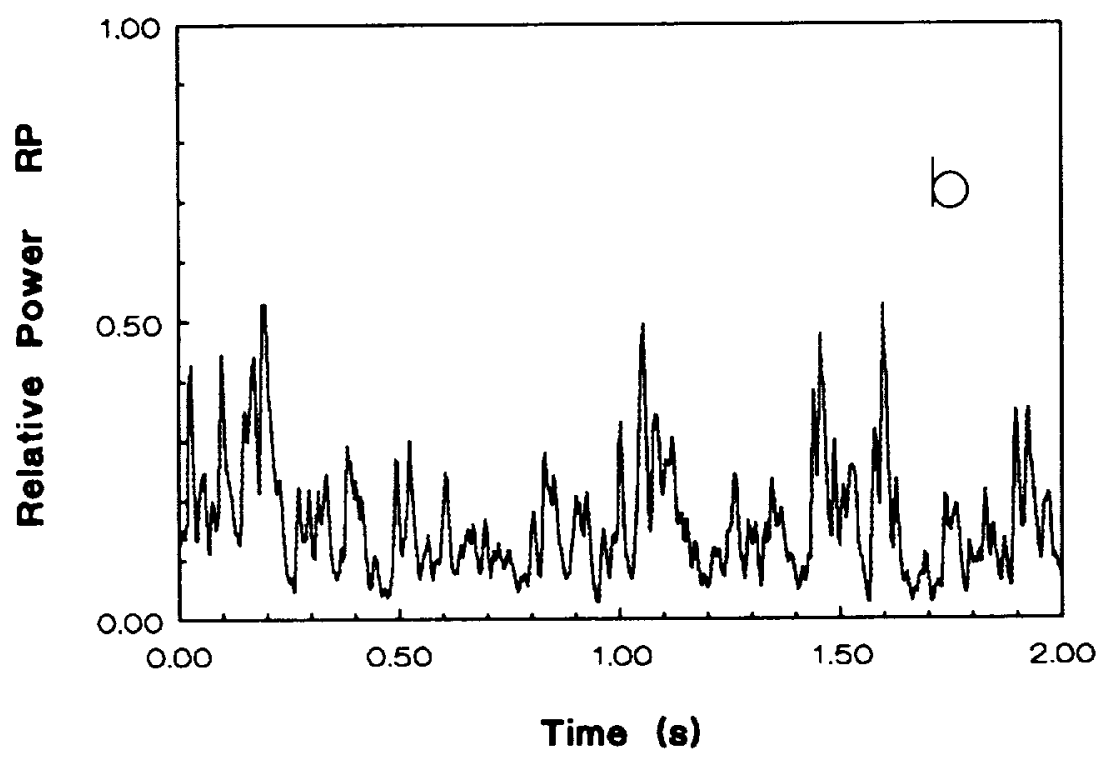

Figure 6.1. 
Scatterometers (30 Deg Inc., VV Pol)

$4.2 \mathrm{~mm}$ diameter drops, $1 \mathrm{~m}$ height

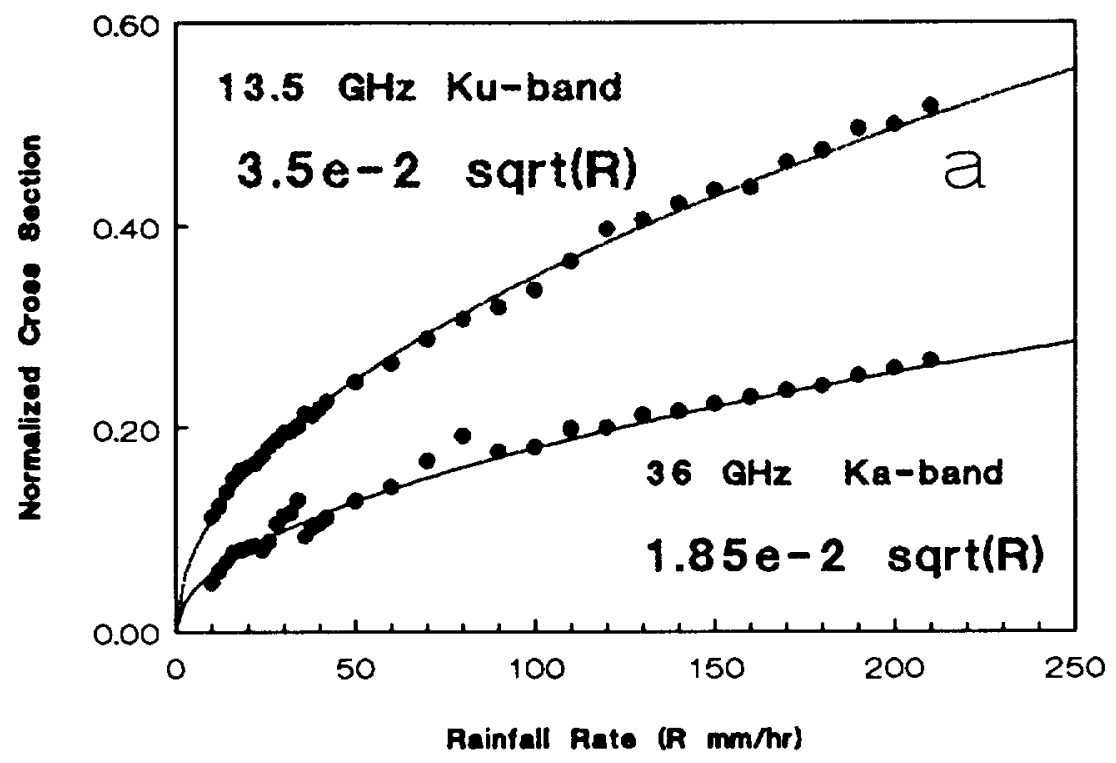

Scatterometers (30 Deg Inc., VV Pol) $4.2 \mathrm{~mm}$ diameter drops, $1 \mathrm{~m}$ height

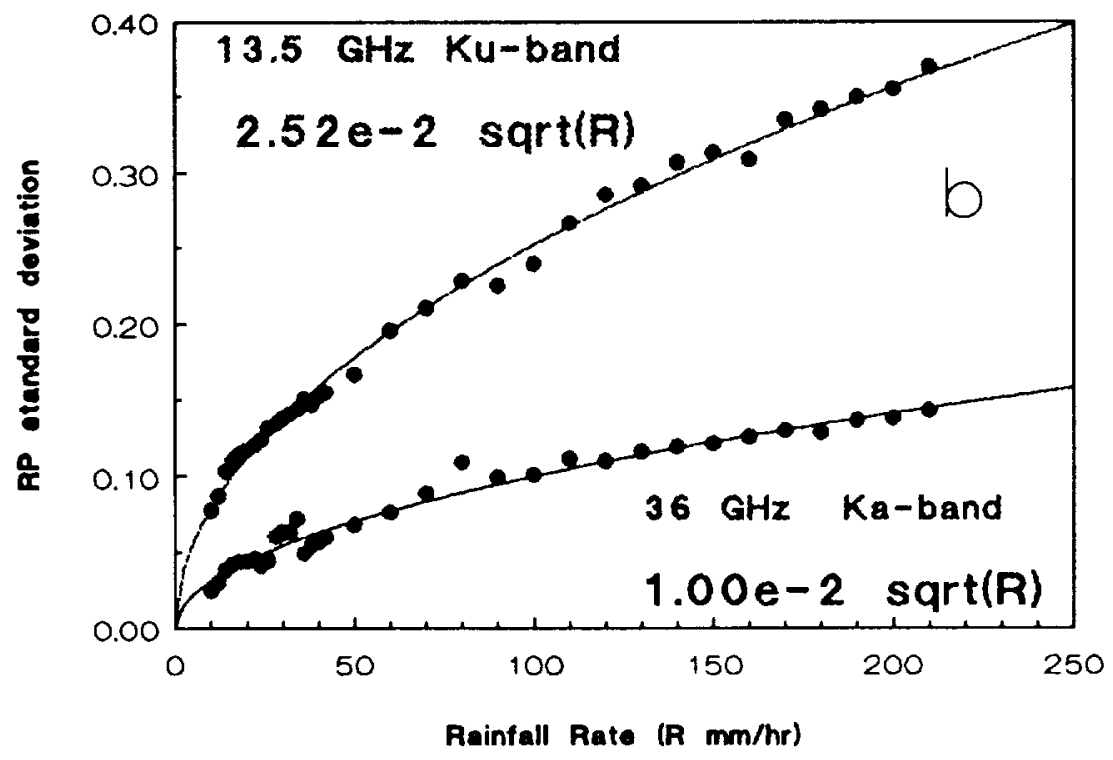

Figure 6.2 . 
Scatterometer PD: Erleng Model Rainfall rate $10 \mathrm{~mm} / 4.2 \mathrm{~mm}$ dia. crop - $13 \mathrm{GHz}$

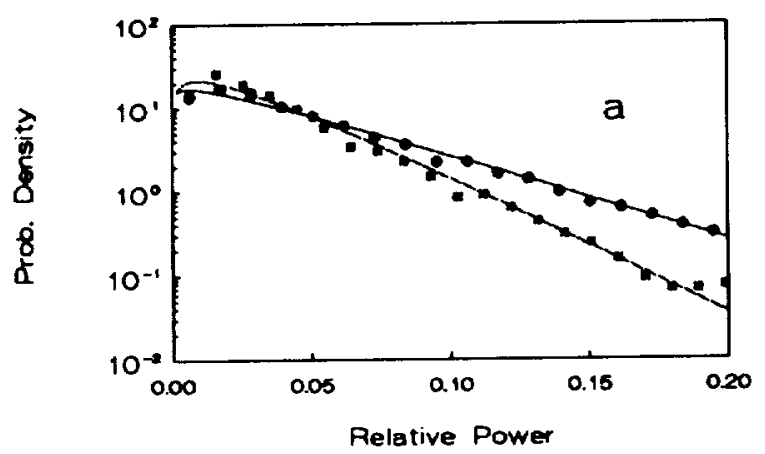

Elevation PD: Erlang Model Rainfall $120 \mathrm{~mm} / \mathrm{m}, 4.2 \mathrm{~mm}$ dia. top - $13 \mathrm{GHz}=36 \mathrm{GHz}$

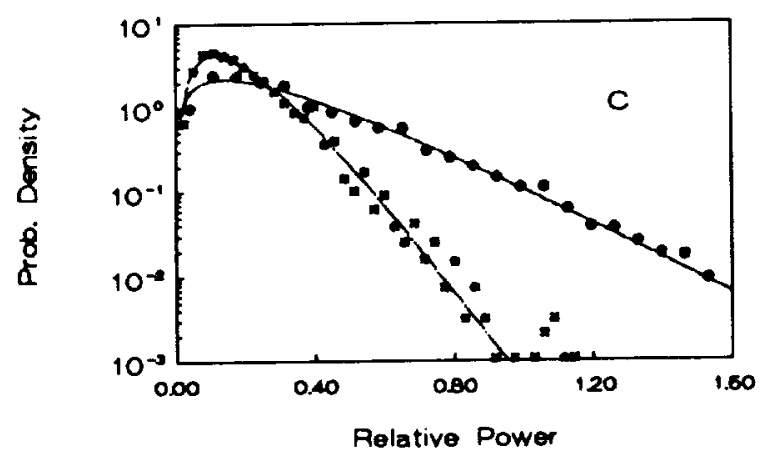

Scatterometer PD: Erlang Model Rainfall rate $42 \mathrm{~mm} / \mathrm{m}$. $4.2 \mathrm{~mm}$ dia. cop

- $13 \mathrm{GHz}$

- $36 \mathrm{GHz}$

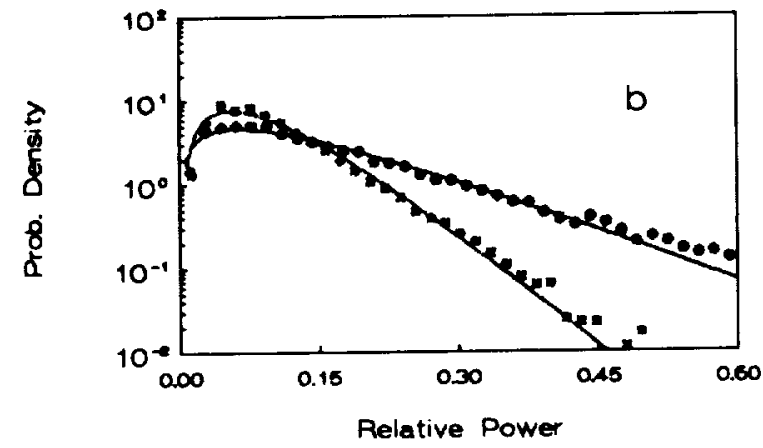

Erlang Model for PDD Rainfall $200 \mathrm{~mm} / \mathrm{hr}, 4.2 \mathrm{~mm}$ dia. drop
- $13 \mathrm{GHz}$
- $36 \mathrm{GHz}$

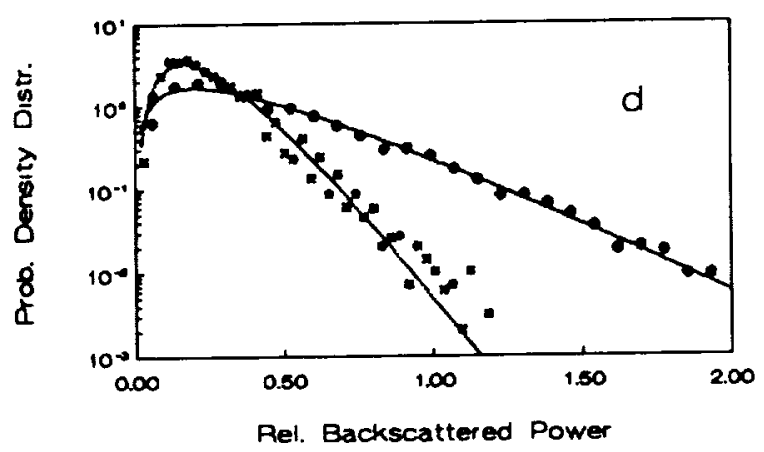

Figure 6.3. 

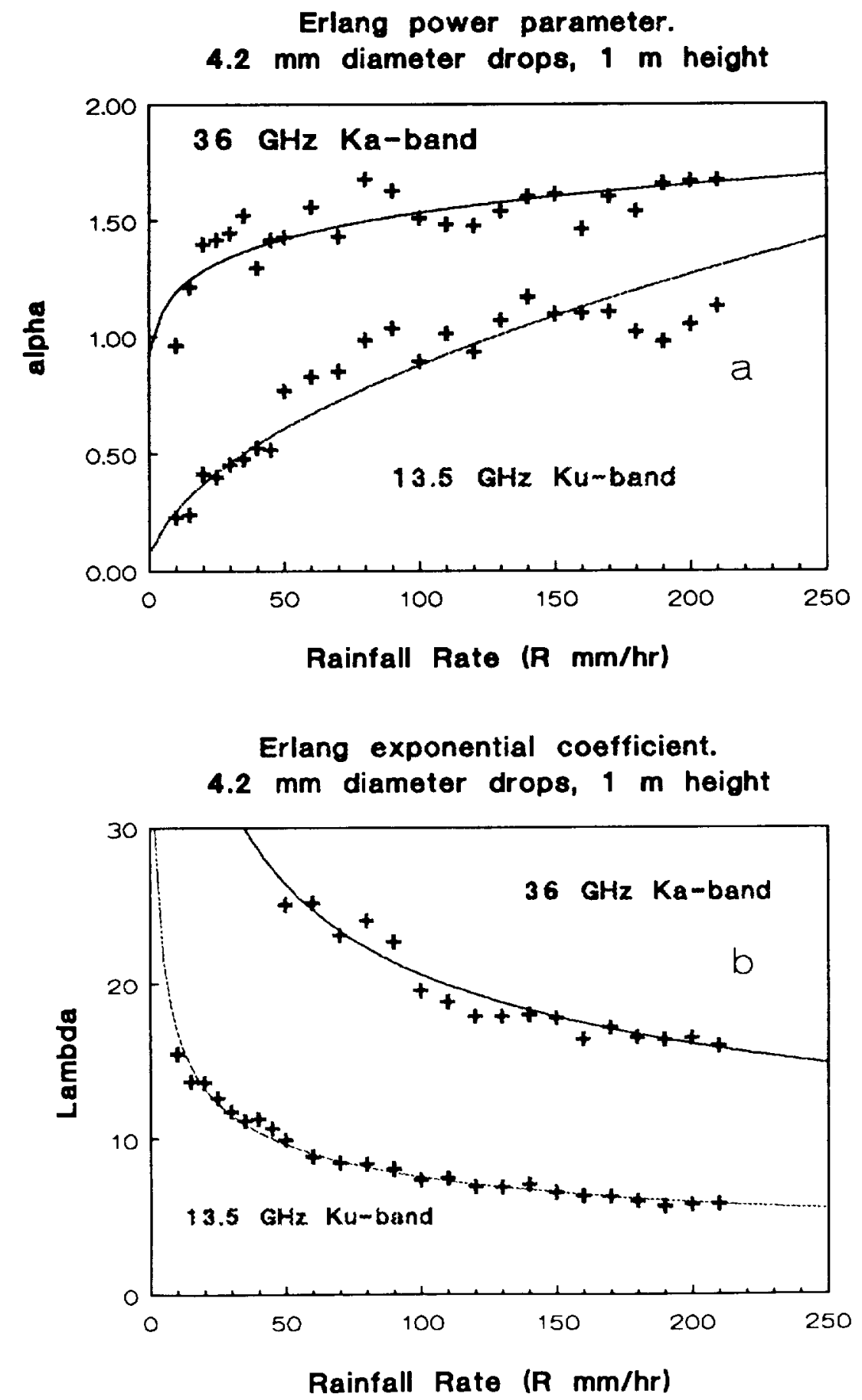

Figure 6.4. 
Public reporting burden for this collection of information is estimatod 10 average 1 hour per response, including the time for reviewing instructions, eaarching existing data sources, gathering and mainteining the date needed, and cornoleting and reviowing the collection of information. Send cormente regardling this burden estimals or any other aspect of this collection of Intormation, Including sugestons for reducing this burden, to Washington Headquarters Services, Directorale for Informalon Operallon: and Reports, 1215 Jefferson Davis Highway, Sulie 1204. Afington, VA 22202-4302, and to the Otice of Managernent and Budget, Paperwork Peduction Project (0704-0189), Washington, DC 20503.

\begin{tabular}{|l|l|l|l} 
1. AGENCY USE ONLY (Leave blenk) & 2. REPORT DATE & 3. REPORT TYPE AND DATES COVERED
\end{tabular}

\begin{tabular}{l|l|l} 
November 1993 & Reference Publication \\
\hline
\end{tabular}

\section{TITLE AND SUBTITLE}

Presenting the Rain-Sea Interaction Facility

6. AUTHOR(S)

Larry F. Bliven and Tonas M. Elfouhaily
5. FUNDING NUMBERS

Code 972
7. PERFORMING ORGANIZATION NAME(S) AND ADDRESS(ES)

Goddard Space Flight Center

Wallops Flight Facility

Wallops Island Virginia

9. SPONSORING/MONITORING AGENCY NAME(S) AND ADDRESS(ES)

National Aeronautics and Space Administration

Washington, D.C. $20546-0001$
8. PERFORMING ORGANIZATION REPORT NUMBER

$94 \mathrm{~B} 00012$

10. SPONSORING/MONITORING AGENCY REPORT NUMBER

NASA RP-1322

\section{SUPPLEMENTARY NOTES}

Tonas M. Elfouhaily: L'Universite de Paris VII and XIII, Paris, France.

12.. DISTRIBUTION/AVAILABILITY STATEMENT

Unclassified-Unlimited

Subject Category 48

Report available from the NASA Center for AeroSpace Information, 800 Elkridge

Landing Road, Linthicum Heights, MD 21090; (301) 621-0390.

\section{ABSTRACT (Maximum 200 words)}

The new Rain-Sea Interaction Facility (RSIF) has been established at GSFC/WFF and the first finds are presented in this report. The unique feature of this laboratory is the ability to systematically study microwave scattering from a water surface roughened by artificial rain, for which the droplets are at terminal velocity. The fundamental instruments and systems (e.g., the rain simulator, scatterometers and surface elevation probes) were installed and evaluated during these first experiments - so the majority of the data were obtained with the rain simulator at $1 \mathrm{~m}$ above the water tank. From these initial experiments, three new models have been proposed: the square-root function for NCS vs. R, the loggaussian model for ring-wave elevation frequency spectrum, and the Erland probability density distribution for backscattered power. Rain rate is the main input for these models, although the coefficients may be dependent upon other factors (drop-size distribution, fall velocity, radar configuration, etc.). The facility is functional and we foresee collaborative studies with investigators who are engaged in measuring and modeling rain-sea interaction processes.

\section{SUBJECT TERMS}

Rain, Ocean, Waves, Ocean Surface Microscale, Scatterometry, Remote Sensing

15. NUMBER OF PAGES

\section{1}

16. PRICE CODE

20. LIMITATION OF ABSTRACT

\begin{tabular}{|c|c|c|}
\hline $\begin{array}{l}\text { 7. SECURITY CLASSIFICATION } \\
\text { OF REPORT }\end{array}$ & $\begin{array}{l}\text { 18. SECURITY CLASSIFICATION } \\
\text { OF THIS PAGE }\end{array}$ & $\begin{array}{l}\text { 19. SECURITY CLASSIFICATION } \\
\text { OF ABSTRACT }\end{array}$ \\
\hline Unclassified & Unclassified & Unclassified \\
\hline
\end{tabular}

Unlimited 